Portland State University

PDXScholar

TREC Final Reports

Transportation Research and Education Center

(TREC)

$11-2011$

\title{
The Relationship Between VMT and Economic Activity
}

B. Starr McMullen

Oregon State University

Nathan Eckstein

Oregon State University

Follow this and additional works at: https://pdxscholar.library.pdx.edu/trec_reports

Part of the Finance and Financial Management Commons, and the Transportation Engineering Commons

Let us know how access to this document benefits you.

\section{Recommended Citation}

McMullen, B. Starr, and Nathan Eckstein. The Relationship Between VMT and Economic Activity. OTRECRR-11-25. Portland, OR: Transportation Research and Education Center (TREC), 2011. https://doi.org/ $10.15760 /$ trec. 45

This Report is brought to you for free and open access. It has been accepted for inclusion in TREC Final Reports by an authorized administrator of PDXScholar. Please contact us if we can make this document more accessible: pdxscholar@pdx.edu. 


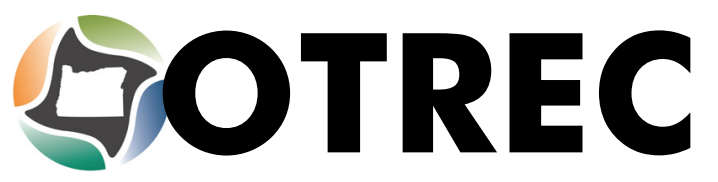

FINAL REPORT

\section{The Relationship Between VMT and Economic Activity}

OTREC-RR-1 1-25

November 2011 



\title{
THE RELATIONSHIP BETWEEN VMT AND ECONOMIC ACTIVITY
}

\author{
FINAL REPORT \\ OTREC-RR-11-25
}

\author{
by \\ B. Starr McMullen, Professor of Economics \\ and Nathan Eckstein, Research Assistant \\ Department of Agricultural and Resource Economics \\ Oregon State University
}

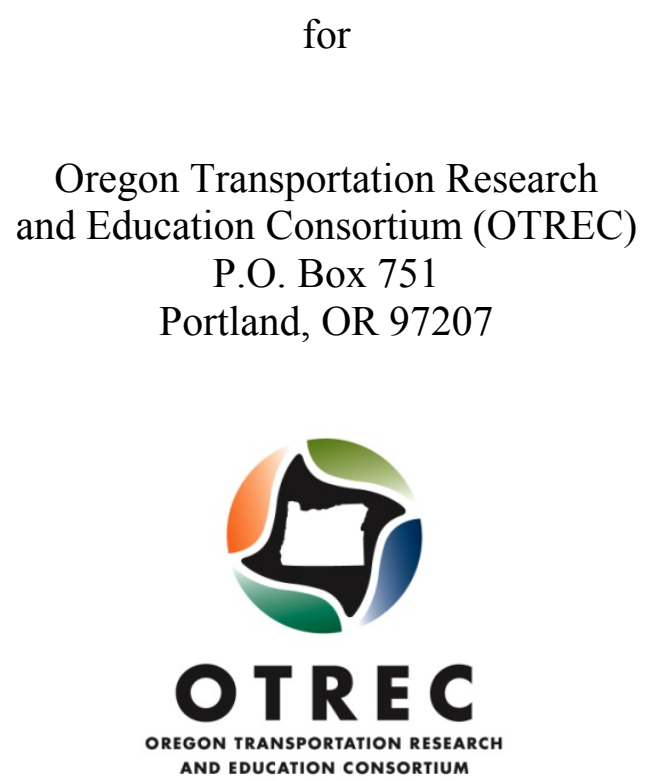

November 2011 



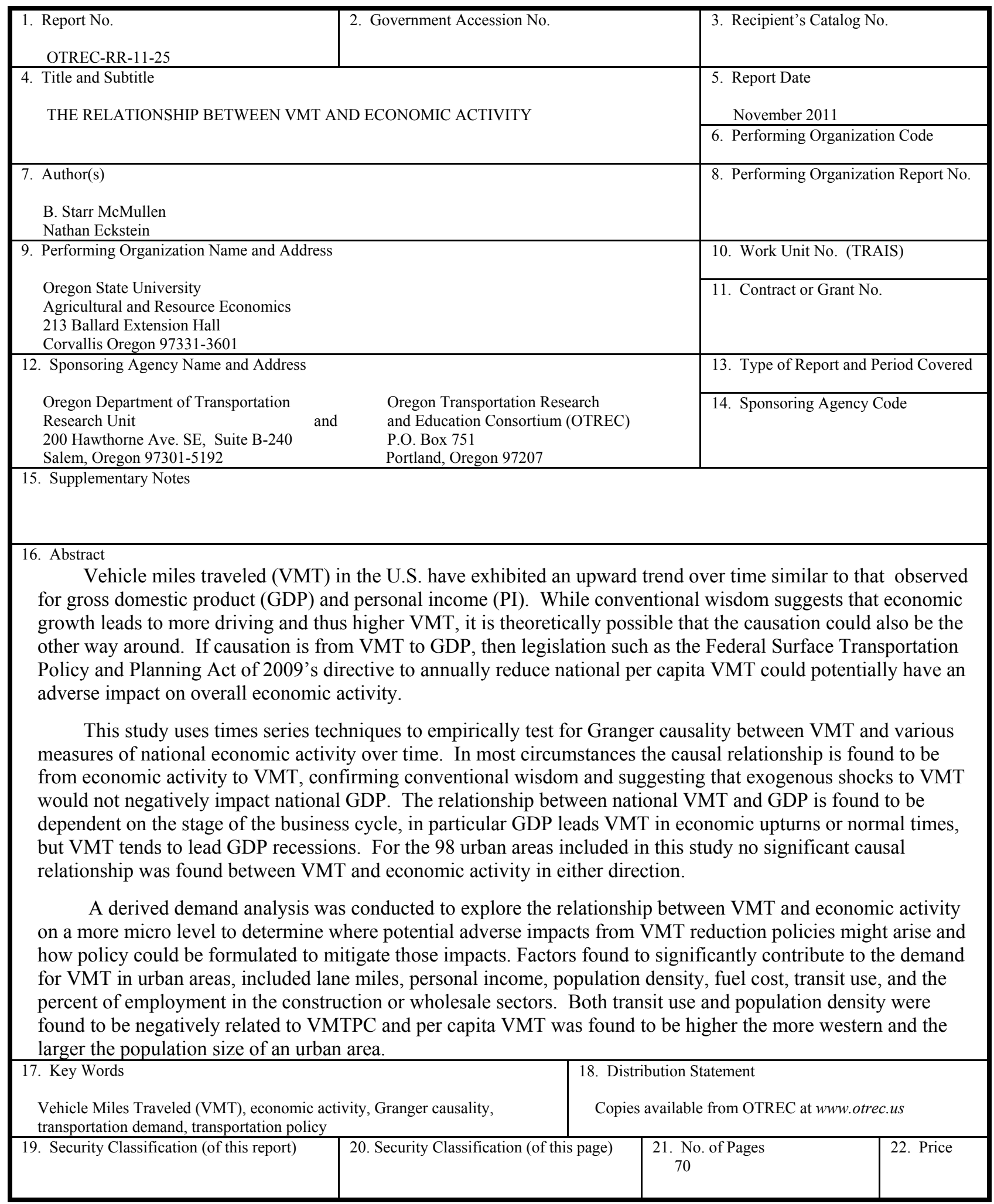




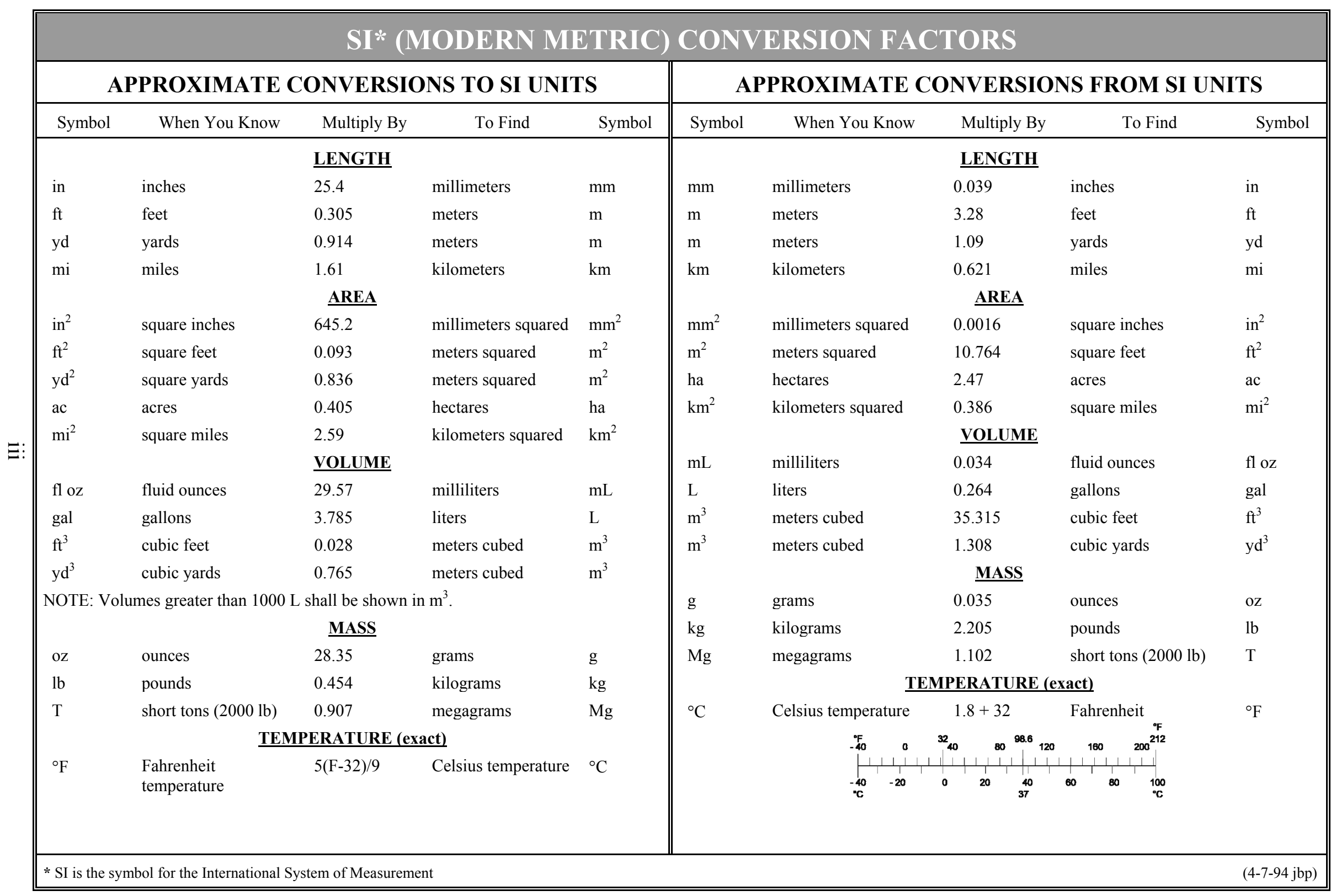




\section{ACKNOWLEDGEMENTS}

The author would like to thank Brian Gregor, Becky Knudson and members of the ODOT Research Unit for their advice and assistance in the preparation of this report. Valuable comments and suggestions were also provided by participants in sessions at the 2011 meetings of the Transportation Research Forum and the OTREC graduate student conference held in Spring 2011.

This project was funded in part by the Oregon Transportation Research and Education Consortium (OTREC). Funding was also provided by a William and Joyce Furman Fellowship for Research in Transportation Economics.

\section{DISCLAIMER}

The contents of this report reflect the views of the authors, who are solely responsible for the facts and the accuracy of the material and information presented herein. This document is disseminated under the sponsorship of the U.S. Department of Transportation University Transportation Centers Program and Oregon State University in the interest of information exchange. The U.S. Government and Oregon State University assume no liability for the contents or use thereof. The contents do not necessarily reflect the official views of the U.S. Government or Oregon State University. This report does not constitute a standard, specification, or regulation. 


\section{THE RELATIONSHIP BETWEEN VMT AND ECONOMIC ACTIVITY}

\section{TABLE OF CONTENTS}

EXECUTIVE SUMMARY ............................................................................................................. 1

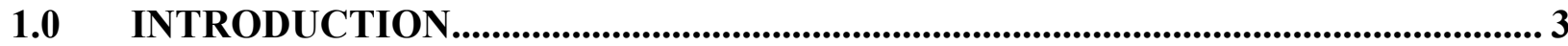

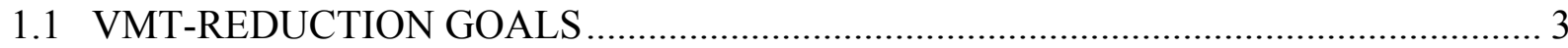

1.2 VMT GROWTH AND ECONOMIC ACTIVITY …………....................................... 4

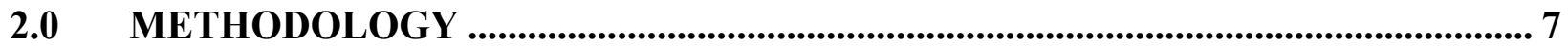

2.1 GRANGER CAUSALITY ……………………………....................................... 7

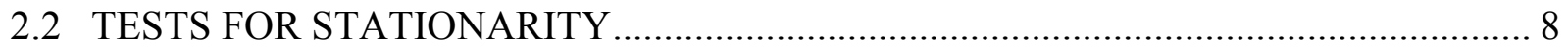

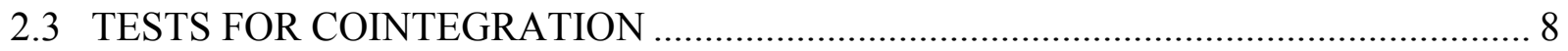

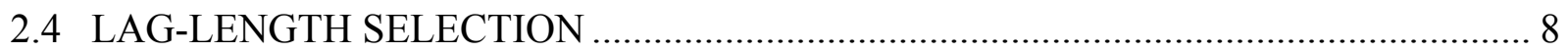

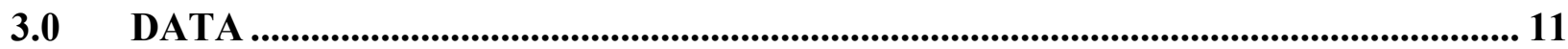

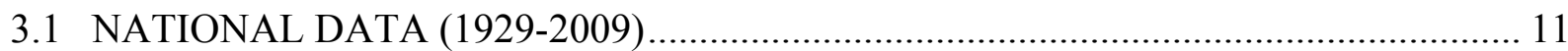

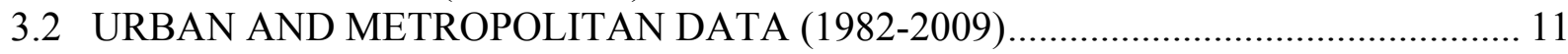

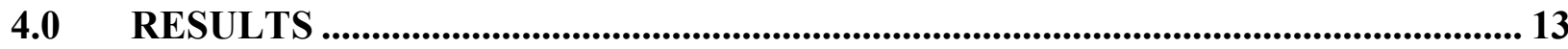

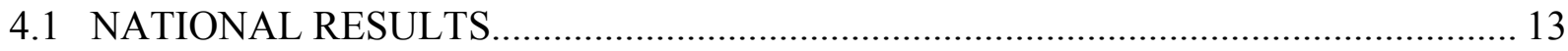

4.2 TESTING FOR A STRUCTURAL BREAK IN THE DATASET ……………............ 147

4.3 IMPACT OF THE BUSINESS CYCLE ON THE VMT/ECONOMIC ACTIVITY





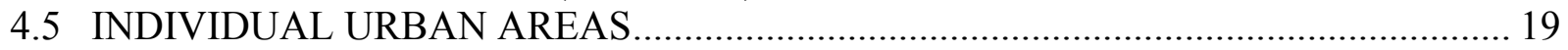

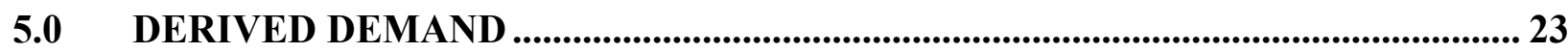

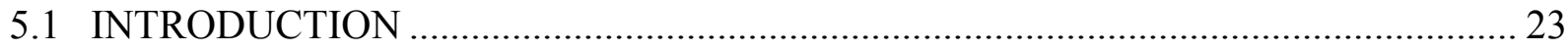

5.1.1 Variable Selection and Expected Relationship with VMT ....................................... 23

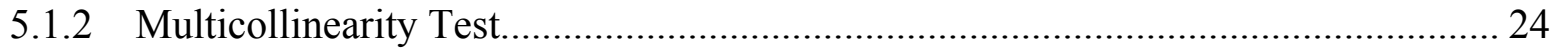

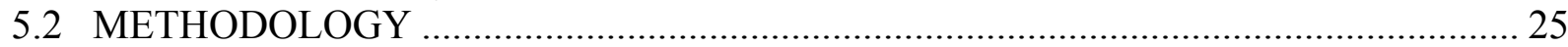

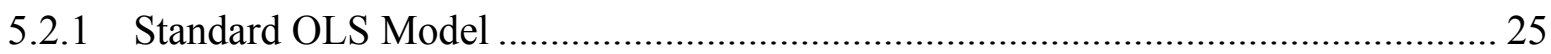

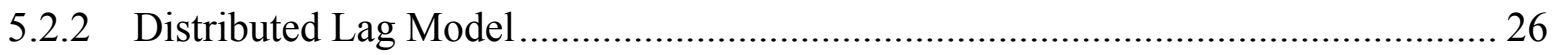

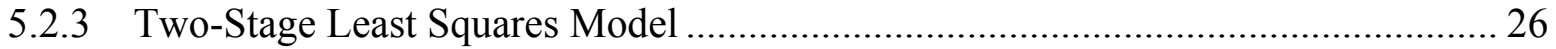

5.3 DATA …

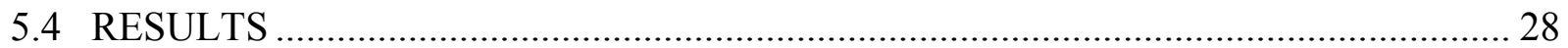

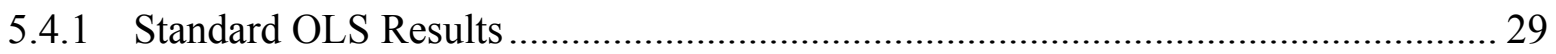

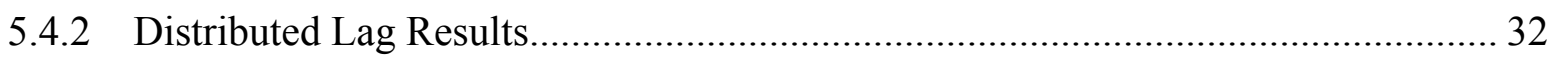

5.4.3 Two-Stage Least Squares Results.......................................................................... 33

5.4.4 Predicted Values Applied to Individual Urban Area Granger Causality ................... 35

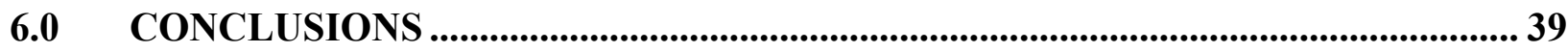

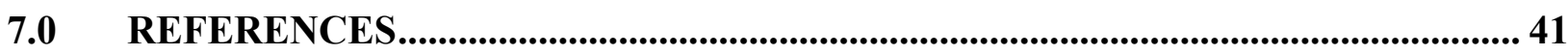

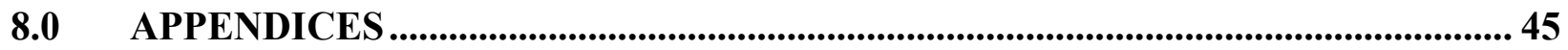




\section{APPENDICES}

APPENDIX A: URBAN AREA POPULATION SIZE AND REGIONAL GROUPINGS

APPENDIX B: STABILITY OF THE VAR MODEL

APPENDIX C: IMPULSE RESPONSE ANALYSIS

APPENDIX D: COEFFICIENTS FOR THE GROUP AND YEARLY FIXED EFFECTS

\section{LIST OF TABLES}

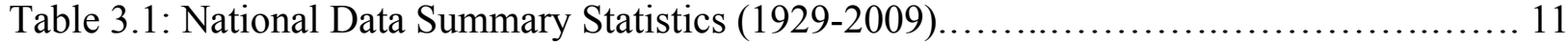

Table 3.2: Sample Urban Area's Daily VMT Summary Statistics (1982-2009)..................... 12

Table 4.1: Augmented Dickey-Fuller Test: National Data (1929-2009) ..................... 15

Table 4.2: Engle-Granger Cointegration Test using ADF: National Data (1929-2009)...........15

Table 4.3: Lag-Length Selection Results: National Data (1929-2009).........................16

Table 4.4: Granger Causality: National Data (1929-2009).............................. 16

Table 4.5: Granger Causality: National Data- Structural Break at 1982 (1949-2007)........... 17

Table 4.6: Granger Causality: National Data-Structural Break with Economic

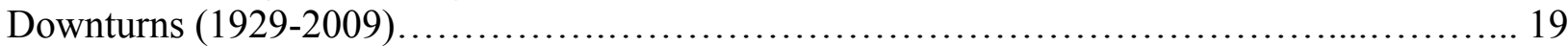

Table 4.7: Augmented Dickey-Fuller Test: 98 Urban Area's Data (1982-2009)................ 20

Table 4.8: Lag-Length Selection Results: 98 Urban Area's Data (1982-2009).................. 20

Table 4.9: Granger Causality: 98 Urban Area's Data (1982-2009)............................. 21

Table 4.10: Granger Causality: Individual Urban Areas (1982-2009).......................... 21

Table 5.1: Sample of 87 Urban Area's Summary Statistics (1982-2009)..................... 30

Table 5.2: Fixed Effects Model with Varying Employment Mix Variables

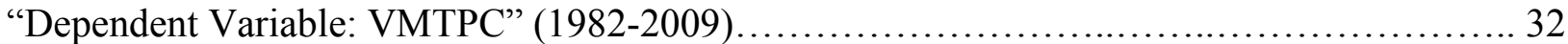

Table 5.3: Fixed Effects Model with Varying Group Effects "Dependent Variable:

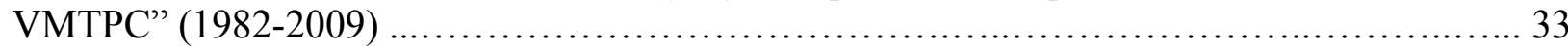

Table 5.4: Distributed Lag Model "Dependent Variable: VMTPC" (1982-2009)................ 34

Table 5.5: 2SLS Model-First Stage "Dependent Variable: LMPC," Instrument: ULA" (1982-

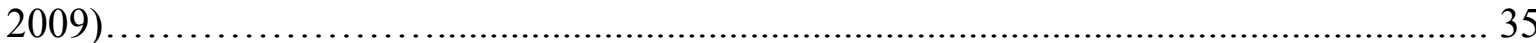

Table 5.6: 2SLS Model with Varying Employment Mix Variables Second Stage

"Dependent Variable: VMTPC", Instrument: ULA" (1982-2009)......................... 36

Table 5.7: Granger Causality Using Predicted Values: Individual Urban Areas (1982-2009)... 37

Table A.1: Urban Areas Population Size Groupings (98 TTI Urban Areas).................. A-1

Table A.2: Urban Areas Regional Groupings (98 Urban Areas)..$\ldots \ldots \ldots \ldots \ldots \ldots \ldots \ldots \ldots \ldots$ A-2

Table B.1: Stability of Eigenvalues ................................................. A-3

Table C.1: Impulse Response Functions (0-20 years post an exogenous VMT shock)........ A-7

Table D.1: Coefficients for the Group and Yearly Fixed Effects from Table 5.6-Column

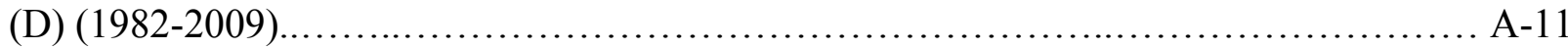

\section{LIST OF FIGURES}

Figure 1.1: U.S. National Real GDP, Real Personal Income and VMT (1929-2009) .................. 4

Figure B.1: Unit Circle Graphs for Stability of Eigenvalues .............................................. A-4

Figure C.1: Impulse Response Function Graph (0-20 years post exogenous VMT shock) ....... A-8 


\section{EXECUTIVE SUMMARY}

Vehicle miles traveled (VMT) in the U.S. have exhibited an upward trend over time similar to that observed for gross domestic product (GDP) and personal income (PI). While conventional wisdom suggests that economic growth leads to more driving and thus higher VMT, it is theoretically possible that the causation could also be the other way around. If causation is from VMT to GDP, then legislation such as the Federal Surface Transportation Policy and Planning Act of 2009's directive to annually reduce national per capita VMT could potentially have an adverse impact on overall economic activity.

This study uses times-series techniques to empirically test for Granger causality between VMT and various measures of economic activity. Care is taken to correctly specify the econometric models and determine the robustness of the results. This is done through stationarity testing, testing for cointegration, lag-length selection testing, and examining differences between various time periods and sub-samples. . In most circumstances the causal relationship is found to be from economic activity to VMT, confirming conventional wisdom and suggesting that exogenous shocks to VMT would not negatively impact national GDP. The relationship between national VMT and GDP is found to be dependent on the stage of the business cycle, in particular GDP leads VMT in economic upturns or normal times, but VMT tends to lead GDP recessions. For the aggregate of the 98 urban areas included in this study no significant causal relationship was found between VMT and economic activity in either direction for most time periods examined in this study.

To explore the relationship between VMT and economic activity on a more micro level a derived demand analysis is applied. This is done by applying a two-stage least squares model that incorporates year and group-specific fixed effects to a panel of 87 urban areas from1982-2009. Multiple factors were found to significantly contribute to the demand for VMT, including lane miles, personal income, population density, fuel cost, transit use, and the percent of employment in the construction or wholesale sectors. Results also indicate that VMT per capita (VMTPC) is higher in urban areas in the western U.S. and in urban areas with larger populations. Both transit use and population density are negatively related to VMTPC, supporting the hypothesis that in less dense areas with inadequate transit there are fewer substitutes for driving so VMT-reduction policies may restrict mobility and have an adverse impact on local economic activity.

Thus, VMT-reduction policies should be carefully formulated considering the heterogeneous nature of the factors that determine the relationship between VMT and economic activity in different urban areas. This study does not imply that VMT reductions can universally be introduced into a transportation system without reducing mobility or economic activity, but suggests that under normal circumstances, in well-developed urban areas, it is reasonable that greenhouse gas (GHG)-related VMT-reduction policies would not result in significant decreases in economic activity. 


\subsection{INTRODUCTION}

Understanding the relationship between vehicle miles traveled (VMT), economic activity and other determinant factors of the demand for driving is essential in the development of an efficient U.S. transportation system. The idea that a transportation system can reduce VMT without reducing mobility or economic activity has recently been a controversial topic in transportation discussions. This study explores this question through an analysis of the relationship between VMT and economic activity. This is done through a statistical analysis of historic U.S. national and urban area VMT, gross domestic product (GDP), and personal income, followed by a more in-depth look at individual urban areas and key factors' effects on the demand for VMT.

The paper is organized as follows: First a review of recent VMT-reduction goals in the U.S. is shown and recent trends in VMT's behavior over time are identified. The next section introduces and explains the statistical methodology pursued in this study and discusses the two datasets: one national and the other a sample of urban areas included in the Texas Transportation Institute's (TTI's) Urban Mobility Report (UMR). Results of Granger causality tests are presented for the national dataset for both the 1929-2009 time period and the 1949-2007 time period that was included in a recent similar study (Pozdena, 2009). Then the causality issue is explored in context to the business cycle and with a sample of 98 urban regions. The analysis is furthered by exploring derived demand of VMT in 87 urban areas in order to help interpret the rational for variations in the Granger causality results. The study concludes with a summary of the primary results, implications for policy and topics for future research in this area.

\subsection{VMT-REDUCTION GOALS}

Both the federal and state governments have proposed reducing VMT to achieve policy objectives. The Federal Surface Transportation Policy and Planning Act of 2009 set a directive to reduce national per capita VMT and to increase public transportation usage, intercity passenger rail services and non-motorized transportation (Commerce Committee, 2009).

At the state level, the Washington state legislature adopted a direct mandate to reduce per capita VMT to 25 percent below 1990 levels by the year 2035 (Winkelman, Bishins and Kooshian, 2009). The Oregon state legislature mandated reductions in GHGs of 10 percent below 1990 levels by 2020 and 75 percent below 1990 levels by 2050, and expects the transportation sector to play a crucial role in the achievement of this goal ( $74^{\text {th }}$ Oregon Legislative Assembly, 2007).

Considering that the U.S. transportation sector accounts for 27 percent of U.S. GHG emissions, 60 percent of which are from light-duty vehicles (Greene and Plotkin, 2011), and that population is expected to increase. Even with increases in fuel efficiency and alternative fuel use, such GHG-reduction targets are not likely to be met without some decrease in VMT (Gregor, 2009).

VMT and measures of economic activity such as GDP, personal income or employment tend to move together, leading to concerns that policies aimed at reductions in VMT will negatively impact economic activity (Pozdena, 2009). However, it has also been argued that demand for 
VMT is a derived demand, so that changes in income lead to changes in VMT and not the other way around. Further, there are many other factors, such as the increased availability of transit, telecommuting, and online retail activity that provide substitutes to mobility, weakening any possible causal link from VMT to GDP (Puentes and Tomer, 2008; Litman, 2010).

Given that VMT reduction is a critical part of several transportation policies, it is essential that the relationship between VMT and economic activity be better understood. If VMT reduction has an adverse impact on economic activity, alternative policy goals need to be considered. It is also possible that the relationship between VMT and economic activity may differ between regions due to differing levels of congestion, transit availability, commute distances and other factors, so that VMT-reduction policies could have different impacts in different locations.

\subsection{VMT GROWTH AND ECONOMIC ACTIVITY}

VMT in the U.S steadily increased between 1929 and the early 2000s when VMT growth began to plateau, experiencing decreases after 2005. The moderation in VMT growth has been noted by others (Polzin, Chu, and Toole-Holt, 2004) and attributed to a variety of factors, notably the maturation of the transportation network and "saturation" of automobile travel in the latter part of the 20th century relative to growth in earlier years. It is also possible that this slowdown was just a precursor of the recession that started in 2007. Figure 1.1 illustrates the upward growth trend in real GDP, real personal income and VMT over the 1929-2009 time period.



FIGURE 1.1: U.S. National Real GDP, Real Personal Income and VMT (1929-2009)

The Texas Transportation Institute (TTI) finds that average daily VMT in urban areas has risen from just over 1.9 billion to over 3.7 billion in 2009, a 51 percent increase over a 28 -year period. The U.S. Department of Energy predicts VMT to increase by 59 percent between 2005 and 2030 if policies are not significantly altered (Gregor, 2009). 
Prior to 2003 VMT grew at similar rates in urban and rural areas, VMT growth rates have since diverged, with urban VMT continuing to grow whereas rural VMT has been falling (Puentes and Tomer, 2008). Thus, the recent policies that aim to curb VMT growth are more relevant for urban areas where continued VMT growth is predicted, as those are the places where congestion and GHG-emission mitigation is most obviously required.

Most models that attempt to predict VMT for policy purposes use a variety of factors, including demographics, automobile ownership, costs of driving, transit availability and real income as determinants of VMT demand (McMullen et al., 2009; Polzin, Chu, and Toole-Holt, 2004). The inclusion of real income is justified by economists because VMT demand is seen as a normal good, suggesting that the causal relationship runs from income to VMT demand (Puentes and Tomer, 2008; Litman, 2010). Thus, in a growing economy an increase in per capita real personal income would be expected to lead to growth in per capita VMT, unless changes in the price of other factors such as fuel cost, car ownership, insurance costs, costs associated with congestion and transit availability have partially offset this effect.

Conversely, VMT can also be considered as an input to production, moving labor, supplies and goods through commuting and freight transport and resulting in additional economic activity. This provides a means by which increases in VMT may lead to increases in income (Pozdena, 2009). Because VMT is used as a proxy for mobility, policies that exogenously enforce decreases in VMT, and thus restrict mobility of the workforce, could have a negative impact on economic activity as measured by income. The latter impact assumes that the decreasing VMT is not accompanied by offsetting levels of substitutes for VMT mobility, such as increased use of alternative transport modes like bicycling, transit, online retailing or telecommuting (Puentes and Tomer, 2008).

Puentes and Tomer (2008) assert that the causation is from output to VMT, not the other way around. They state that in modern times, decreases in VMT for large geographic regions will not be an indicator of declining economic activity. Additionally, Litman (2010) argues that while increased wealth often increases energy use and vehicle travel, this does not mean that increases in vehicle travel will increase wealth or that reductions in vehicle travel reduce wealth (Litman, 2010).

However, Pozdena (2009) contends that VMT significantly causes economic activity and that implementing VMT reduction to achieve GHG-reduction mandates could have an adverse impact on the economy. Pozdena (2009) is the only one to employ a valid econometric methodology to pursue this question, using pairwise Granger causality testing. During the 19492007 time period, he reports significant bidirectional causality, meaning that VMT and the economy Granger "cause" each other. Using impulse response functions, he estimates a downward shock to VMT - such as one due to GHG regulation - to result in a 90 percent reduction of GDP, the size of the VMT shock in the short run (two years) and 46 percent in the long run (20 years) (Pozdena, 2009).

Although Pozdena (2009) uses statistical techniques to examine this causal relationship, his paper does not provide alternative specifications to determine the robustness of his results. As shown below, standard statistical tests can be used to select preferred model specifications. In particular, the lag structures recommended by standard tests differ from those reported by 
Pozdena, which may affect his reported results. Furthermore, results are also shown to be sensitive to the exact time period included in the statistical analysis. 


\subsection{METHODOLOGY}

The purpose of this study is to more fully explore the relationship between VMT and economic activity as measured by GDP and personal income using time-series techniques and testing for Granger causality. This study expands on previous work in several ways:

- The study uses well-established statistical techniques for testing for stationarity, cointegration and the selection of the appropriate lag structure in the time-series data.

- The study tests for a structural change in the relationship between VMT and economic activity during the post-WWII 1949-2007 time period.

- The study examines the sensitivity of the Granger causality results to the stage of the macroeconomic business cycle.

- Both national and urban datasets are provided in this paper. Furthermore, urban results are broken down and reported by size as defined by TTI.

- Finally, demand for VMT is derived at the urban level to provide additional rational to some of the variation in the Granger causality results for different areas.

The Granger causality methodology is first introduced along with the various tests that must be performed in order to deal with time-series data and model specification.

\subsection{GRANGER CAUSALITY}

Granger causality provides an analytical tool with which time precedence can be established between variables (Granger, 1969). Time precedence is one of the bases of causation; yet, due to Granger causality being defined in terms of predictability, it is not an acceptable definition of causation in its own right (Bunge, 1959). The identification problem of differentiating between correlation and causation needs economic theory and institutional knowledge to be solved, but econometric testing through Granger causality can provide a good start (Stock, 2001).

The Granger test provides probability $>C h i^{2}$ values for the F-statistics testing whether all the included lags of an endogenous variable in a vector auto-regression (VAR) are jointly significant. The reduced-form VAR model is shown below in the system of two equations.

$$
\begin{array}{r}
\log \left(V M T_{t}\right)=C_{1}+A_{11} * \log \left(V M T_{t-1}\right)+A_{12} * \log \left(V M T_{t-2}\right)+ \\
A_{13} * \log \left(G D P_{t-1}\right)+A_{14} * \log \left(G D P_{t-2}\right)+e_{t} \\
\log \left(G D P_{t}\right)=C_{2}+A_{21} * \log \left(V M T_{t-1}\right)+A_{22} * \log \left(V M T_{t-2}\right)+ \\
A_{23} * \log \left(G D P_{t-1}\right)+A_{24} * \log \left(G D P_{t-2}\right)+e_{t}
\end{array}
$$


The null hypothesis is that the lagged variable's coefficients are equal to zero or, in other words, that past values of one variable do not help explain the other variable's future movements. Therefore, any probability $>C h i^{2}$ result less than or equal to the significance level of 5 percent (0.05) affords the conclusion that the lagged variable Granger causes the dependent variable. Where causality is defined as $\mathrm{Y}$ causing $\mathrm{X}$ if $\mathrm{X}$ can be better predicted using all available information rather than if the information apart from Y had been used (Granger, 1969).

\subsection{TESTS FOR STATIONARITY}

Since time-series data such as that shown in Figure 1.1 tend to trend upwards over time, they must be tested for stationarity and made stationary, usually using differences, prior to use in a VAR model. Data is said to be stationary when it displays a stable and observable mean and variance over time (Dickey and Fuller, 1979). A stationary time-series is categorized as being integrated of order zero, written as $\mathrm{I}(0)$, or is said to have no unit roots; this quality in a timeseries vector is a prerequisite for use in a standard VAR model. Alternatively, nonstationary data features a shifting mean and variance over time. Unit root tests provide the order of integration of a variable. A time-series that is categorized as integrated of order "P," written as $\mathrm{I}(\mathrm{P})$, would need to be differenced "P" times to become a stationary process or I(0) (Hamilton, 1994).

An augmented Dickey-Fuller test with a null hypothesis that the variable contains a unit root and an alternative hypothesis that the variable was generated by a stationary process is applied to all time-series prior to use in the VAR. MacKinnon approximate p-values of the augmented Dickey-Fuller test statistic that are less than or equal to the significance level of 10 percent $(0.10)$ indicate that the null hypothesis can be rejected, suggesting stationarity.

\subsection{TESTS FOR COINTEGRATION}

Cointegration is said to occur when some linear combination of two or more time-series has a lower order of integration than the time-series have individually. This can happen if the two time-series share a common stochastic drift. If cointegration is present between two or more variables, these variables should not be used in a standard VAR model (Engle and Granger, 1987). To test for cointegration an Engle-Granger cointegration test is applied that uses an augmented Dickey-Fuller test on the residuals of a regression featuring two possibly cointegrated variables. Recall that all national variables are I(1); therefore, if a linear combination of the two creates an $\mathrm{I}(0)$ time-series the two variables are defined as cointegrated.

\subsection{LAG-LENGTH SELECTION}

The lag-length selection for the VAR model is made through the use of the several tests found in the "Varsoc" command in the Stata 11.1 (64-bit) Data Analysis and Statistical Software Program. Since Pozdena (2009) uses lags of four years, four years is used as the maximum possible lag-length tested for significance in this paper, although, prior studies on GDP consistently have used only one- or two-year lags for this type of VAR (Blanchard, 2009). Five test statistics are used to help determine the longest lag that continues to contribute to the explanation of a VAR. Consequently, if three years is found to be the appropriate lag-length, lags of one, two and three years all significantly explain the VAR and need to be included in the model specification. 
The five statistical tests for lag-lengths include the final prediction error (FPE); Akaike's information criterion (AIC); Schwarz's Bayesian information criterion (SBIC); the Hannan and Quinn information criterion (HQIC); and the Likelihood Ratio (LR). For further description of the tests see Ivanov and Killen (2005). In situations where all tests do not agree on lag-length AIC always selects the largest order, SBIC always selects the smallest and HQIC is somewhere in between (Lütkepohl, 2005). When this occurs, the HQIC's selection is used in this analysis. 


\subsection{DATA}

\subsection{NATIONAL DATA (1929-2009)}

The Bureau of Economic Analysis (BEA) provides annual U.S. GDP and personal income data from 1929 to the present (U.S. Department of Commerce, 2011). Both GDP and personal income are expressed throughout this study in terms of real 2005 dollars in order to control for inflation. The Federal Highway Administration (FHWA) publishes annual estimates of U.S. national VMT over the same time period (U.S. Department of Transportation, 2011). In this study six variables are explored at the national level; VMT, real GDP, real PI, and the per capita forms of these three variables (VMTPC, GDPPC, PIPC). Table 3.1 displays general summary statistics for the national data; providing mean, standard deviation, minimum, maximum and percent annual growth from 1929-2009. This is the same data used by Pozdena (2009) except that he used the 1949-2007 sub-period.

Table 3.1: National Data Summary Statistics (1929-2009)

\begin{tabular}{l|r|r|r|r|r}
\hline Variable Name & \multicolumn{1}{|c|}{ Mean } & Std. Dev. & \multicolumn{1}{c|}{ Min } & \multicolumn{1}{c|}{ Max } & \multicolumn{1}{c}{$\begin{array}{c}\text { Annual } \\
\text { Growth }\end{array}$} \\
\hline Daily VMT $(000,000)$ & 3,540 & 2,600 & 542 & 8,350 & $3.64 \%$ \\
\hline Daily VMTPC & 15.21 & 8.03 & 4.16 & 27.94 & $2.45 \%$ \\
\hline Annual VMT $(000,000)$ & $1,250,000$ & 920,000 & 198,000 & $3,050,000$ & $3.64 \%$ \\
\hline Annual VMTPC & 5,445 & 2,888 & 1,518 & 10,168 & $2.45 \%$ \\
\hline GDP $(000,000)$ & $\$ 5,160,000$ & $\$ 3,770,000$ & $\$ 716,000$ & $\$ 13,200,000$ & $3.40 \%$ \\
\hline GDPPC & $\$ 22,292$ & $\$ 11,228$ & $\$ 5,700$ & $\$ 43,800$ & $2.21 \%$ \\
\hline PI $(000,000)$ & $\$ 4,260,000$ & $\$ 3,240,000$ & $\$ 594,000$ & $\$ 11,400,000$ & $3.45 \%$ \\
\hline PIPC & $\$ 18,261$ & $\$ 9,750$ & $\$ 4,730$ & $\$ 37,400$ & $2.26 \%$ \\
\hline Population $(000,000)$ & 203 & 57.1 & 122 & 308 & $1.16 \%$ \\
\hline
\end{tabular}

\subsection{URBAN AND METROPOLITAN DATA (1982-2009)}

The data for urban areas has been collected and published by the TTI since 1982 for use in their annual Urban Mobility Report (UMR) (Texas Transportation Institute, 2011). From this dataset, average daily VMT on freeways and principal arterial roads is used as the urban VMT variable for this study. These VMT estimates are compiled by TTI from the Highway Performance Monitoring System (HPMS) database, and other local transportation data sources and are put into per capita form using population estimates from the U.S. Census Bureau.

Because urban GDP data is unavailable, this study substituted metropolitan statistical area (MSA) personal income data for the MSAs that coincide with the TTI urban areas. Note that at the national level, correlation between personal income and GDP is .999, making PI a good proxy for GDP. See U.S. Census Bureau (2010) and Office of Budget and Management (2010) for urban area and MSA definitions. Personal income, in real 2005 dollars, is also from the BEA (U.S. Department of Commerce, 2011). 
TTI collects detailed data on 100 individual urban areas in the U.S. and categorizes these urban areas into four population size groupings: very large (vlg), large (lrg), medium (med) and small (sml) (see Appendix A for categorical definitions and a list of urban areas in each group). These groupings are important, as it is likely that VMT-reduction policies will be implemented in larger urban areas first because they have the largest GHG-reduction potential and also suffer the worst congestion delays. Thus, it is important to observe if variations in the size of an urban area affects the causal relationship between VMT and economic activity. Only 98 of these 100 urban areas were included in this study because two are not core urban areas inside a MSA. Without this distinction, personal income data is not available.

Table 3.2 provides summary average annual statistics for VMT, PI and population variables in the 98 TTI urban areas for the period 1982-2009. While personal income per capita has grown in all urban areas, the growth has been fastest in the largest areas and slowest in the small urban areas.. These 98 urban areas are incorporated into the study in several ways. All 98 areas are given as one aggregate time-series, as well as four population size groupings. They are analyzed individually and are further refined into a 87 urban-area panel dataset in the derived demand chapter of this paper.

Table 3.2 Sample Urban Area's Daily VMT Summary Statistics (1982-2009)

\begin{tabular}{l|r|r|r|r|r}
\hline Variable Name & \multicolumn{1}{c|}{ Mean } & \multicolumn{1}{c}{ Std. Dev. } & \multicolumn{1}{c}{ Min } & \multicolumn{1}{c}{ Max } & \multicolumn{1}{c}{$\begin{array}{c}\text { \% Annual } \\
\text { Growth }\end{array}$} \\
\hline VMT & $23,200,000$ & $33,100,000$ & 550,000 & $268,000,000$ & $2.75 \%$ \\
\hline VMT (vlg) & $83,600,000$ & $52,900,000$ & $24,000,000$ & $268,000,000$ & $2.55 \%$ \\
\hline VMT (lrg) & $23,200,000$ & $10,700,000$ & $4,700,000$ & $61,600,000$ & $3.08 \%$ \\
\hline VMT (med) & $10,000,000$ & $4,288,686$ & $1,720,000$ & $26,100,000$ & $2.89 \%$ \\
\hline VMT (sml) & $4,914,278$ & $2,563,854$ & 550,000 & $11,800,000$ & $2.96 \%$ \\
\hline VMTPC & 16.50 & 3.84 & 5.50 & 29.51 & $1.32 \%$ \\
\hline VMTPC (vlg) & 16.55 & 3.78 & 7.01 & 24.32 & $1.33 \%$ \\
\hline VMTPC (lrg) & 16.72 & 3.34 & 8.01 & 23.86 & $1.52 \%$ \\
\hline VMTPC (med) & 16.53 & 3.67 & 5.76 & 26.18 & $1.30 \%$ \\
\hline VMTPC (sml) & 16.14 & 4.58 & 5.50 & 29.51 & $1.14 \%$ \\
\hline UA Pop. & $1,436,062$ & $2,267,139$ & 95,000 & $18,800,000$ & $1.34 \%$ \\
\hline UA Pop. (vlg) & $5,416,923$ & $3,962,287$ & $1,430,000$ & $18,800,000$ & $1.20 \%$ \\
\hline UA Pop. (lrg) & $1,366,139$ & 510,278 & 365,000 & $3,048,000$ & $1.54 \%$ \\
\hline UA Pop. (med) & 592,735 & 164,021 & 170,000 & $1,100,000$ & $1.57 \%$ \\
\hline UA Pop. (sml) & 286,997 & 947,378 & 95,000 & 510,000 & $1.79 \%$ \\
\hline PI (000,000) & $\$ 59,700$ & $\$ 95,300$ & $\$ 136,000$ & $\$ 959,000$ & $2.70 \%$ \\
\hline PI (vlg) (000,000) & $\$ 209,000$ & $\$ 45,700$ & $\$ 134,000$ & $\$ 282,000$ & $2.67 \%$ \\
\hline PI (lrg) (000,000) & $\$ 54,800$ & $\$ 12,900$ & $\$ 34,500$ & $\$ 74,700$ & $2.83 \%$ \\
\hline PI (med) (000,000) & $\$ 25,100$ & $\$ 5,030$ & $\$ 16,900$ & $\$ 33,100$ & $2.48 \%$ \\
\hline PI (sml) (000,000) & $\$ 13,600$ & $\$ 3,230$ & $\$ 8,750$ & $\$ 18,800$ & $2.83 \%$ \\
\hline PIPC & $\$ 31,204$ & $\$ 7,112$ & $\$ 11,822$ & $\$ 74,954$ & $1.43 \%$ \\
\hline PIPC (vlg) & $\$ 36,845$ & $\$ 4,577$ & $\$ 28,289$ & $\$ 44,396$ & $1.48 \%$ \\
\hline PIPC (lrg) & $\$ 32,174$ & $\$ 3,982$ & $\$ 25,039$ & $\$ 38,134$ & $1.41 \%$ \\
\hline PIPC (med) & $\$ 31,191$ & $\$ 3,618$ & $\$ 24,589$ & $\$ 37,022$ & $1.41 \%$ \\
\hline PIPC (sml) & $\$ 28,242$ & $\$ 3,306$ & $\$ 22,433$ & $\$ 33,333$ & $1.34 \%$ \\
\hline MSA Pop. & $1,730,465$ & $2,396,915$ & 111,106 & $19,100,000$ & $1.24 \%$ \\
\hline MSA Pop. (vlg) & $5,599,903$ & 551,734 & $4,742,498$ & $6,492,596$ & $1.17 \%$ \\
\hline MSA Pop. (lrg) & $1,681,714$ & 196,184 & $1,376,848$ & $2,004,722$ & $1.40 \%$ \\
\hline MSA Pop. (med) & 795,784 & 69,622 & 686,925 & 911,835 & $1.05 \%$ \\
\hline MSA Pop. (sml) & 475,742 & 58,862 & 389,911 & 578,215 & $1.47 \%$ \\
\hline & & & & & \\
\hline
\end{tabular}




\subsection{RESULTS}

Results are presented in five sub-sections. First, U.S. national VMT, GDP and PI data are analyzed for 1929-2009 and then for the 1949-2007 time period for comparison with Pozdena (2009). Next, a Chow test is used to test for and confirm a structural break in the relationship between VMT and GDP in approximately 1982, the year in which the TTI data for urban areas became available. The impact of the macroeconomic business cycle on the national Granger causality tests is then explored, followed by analysis of Granger causality for the sample of 98 U.S. urban areas. Finally, each of the 98 urban areas is tested individually for Granger causality.

\subsection{NATIONAL RESULTS}

The augmented Dickey-Fuller test was used to test for the stationarity of logged variables from aggregate national 1929-2009 data. Results shown in Table 4.1 indicate that all six national variables are integrated of order one, I(1), and thus are stationary as logged first differences.

Table 4.1 Augmented Dickey-Fuller Test: National Data (1929-2009)

\begin{tabular}{l|c|c|c}
\hline \multirow{2}{*}{ Variable Name } & \multicolumn{2}{|c|}{ MacKinnon approximate p-value for Z(t) } & \multirow{2}{*}{ Order of Integration } \\
\cline { 2 - 3 } & Logged Levels & Logged Differences & \\
\hline VMT & 0.6337 & $0.0000^{*}$ & $\mathrm{I}(1)$ \\
\hline VMTPC & 0.6067 & $0.0000^{*}$ & $\mathrm{I}(1)$ \\
\hline GDP & 0.8512 & $0.0000^{*}$ & $\mathrm{I}(1)$ \\
\hline GDPPC & 0.8371 & $0.0000^{*}$ & $\mathrm{I}(1)$ \\
\hline PI & 0.9094 & $0.0000^{*}$ & $\mathrm{I}(1)$ \\
\hline
\end{tabular}

* Represents statistical significance at 10\% level (H1: stationarity)

Table 4.2 displays the MacKinnon approximate p-value for the augmented Dickey-Fuller test statistic found in the Engle-Granger cointegration test. Results indicate that that no cointegration exists between any of the relevant variable pairs because linear combinations of the variable pairs do not have lower orders of integrations than the individual I(1) variables. Thus, a standard reduced form VAR model may be applied to this national dataset.

Table 4.2: Engle-Granger Cointegration Test using ADF: National Data (1929-2009)

\begin{tabular}{l|c|c|c}
\hline \multirow{2}{*}{ Variable Name } & \multicolumn{2}{|c|}{ MacKinnon approximate $\mathrm{p}$-value for $\mathrm{Z}(\mathrm{t})=$} & \multirow{2}{*}{ Cointegration } \\
\cline { 2 - 3 } & Logged Levels & Order of Integration & No \\
\hline VMT-GDP residuals & 0.1690 & $\mathrm{I}(1)$ & No \\
\hline VMTPC-GDPPC residuals & 0.1765 & $\mathrm{I}(1)$ & No \\
\hline VMT-GDPPC residuals & 0.2032 & $\mathrm{I}(1)$ & No \\
\hline VMTPC-GDP residuals & 0.1579 & $\mathrm{I}(1)$ & No \\
\hline VMT-PI residuals & 0.1601 & $\mathrm{I}(1)$ & No \\
\hline VMTPC-PIPC residuals & 0.1717 & $\mathrm{I}(1)$ & No \\
\hline VMT-PIPC residuals & 0.1774 & $\mathrm{I}(1)$ & No \\
\hline VMTPC-PI residuals & 0.1652 & $\mathrm{I}(1)$ & \\
\hline
\end{tabular}

No results statistically significant at the 10\% level (Null hypothesis of no cointegration fails to be rejected) 
The results of all five tests for lag structure were analyzed in Table 4.3. Although not all test statistics agree on lag-length, the HQIC test indicated a two-year lag-length in every regression at the national level. Thus a two-year lag-length is used; a choice consistent with past GDP timeseries studies (Blanchard, 2009), but not with Pozdena's (2009) choice of two- and four-year lags.

Table 4.3: Lag-Length Selection Results: National Data (1929-2009)

\begin{tabular}{l|c}
\hline Regression Name & Suggested Lag-Length (Test Abbreviations) \\
\hline VMT-GDP & 2 lags* (LR, FPE, AIC, HQIC, and SBIC) \\
\hline VMTPC-GDPPC & 2 lags* (LR, FPE, AIC, HQIC, and SBIC) \\
\hline VMT-GDPPC & 2 lags* (LR, FPE, AIC, HQIC, and SBIC) \\
\hline VMTPC-GDP & 2 lags* (LR, FPE, AIC, HQIC, and SBIC) \\
\hline VMT-PI* & 2 lags* (LR, HQIC, SBIC) 3 lags (FPE, AIC) \\
\hline VMTPC-PIPC** & 2 lags* (LR, HQIC, SBIC) 3 lags (FPE, AIC) \\
\hline VMT-PIPC** & 2 lags* (LR, HQIC, SBIC) 4 lags (FPE, AIC) \\
\hline VMTPC-PI* & 2 lags* (LR, HQIC, SBIC) 3 lags (FPE, AIC) \\
\hline
\end{tabular}

* Represents the lag-length selected for use in the VAR

**Represents that the variables were additionally tested using the longer lag-lengths; resulting in no significant changes in the Granger causality findings.

The Granger causality results shown in Table 4.4 indicate economy activity consistently causes VMT, but no statistically significant reverse causation from VMT to economic activity exists for the 1929-2009 time span. These results are significant at the 5 percent level and robust across alternative measures of economic activity (GDP, GDPPC, PI and PIPC). All Granger causality results presented in this study are taken from VARs with stable eigenvalues (see Appendix B). These results follow the rationale that VMT is a normal good and further suggest that as economic activity increases so does personal vehicle driving. However, they do not support the hypothesis that reductions in VMT would significantly impact economic activity.

Table 4.4: Granger Causality: National Data (1929-2009)

\begin{tabular}{l|c|c}
\hline \multirow{2}{*}{ Regression Name } & \multicolumn{2}{|c}{ Probability $>$ Chi2 } \\
\cline { 2 - 3 } & VMT causes Economy & Economy causes VMT \\
\hline VMT-GDP & 0.138 & $0.034^{*}$ \\
\hline VMTPC-GDPPC & 0.158 & $0.028^{*}$ \\
\hline VMT-GDPPC & 0.147 & $0.026^{*}$ \\
\hline VMTPC-GDP & 0.148 & $0.037^{*}$ \\
\hline VMT-PI & 0.109 & $0.010^{*}$ \\
\hline VMTPC-PIPC & 0.181 & $0.013^{*}$ \\
\hline VMT-PIPC & 0.167 & $0.011^{*}$ \\
\hline VMTPC-PI & 0.119 & $0.011^{*}$ \\
\hline
\end{tabular}

* Represents statistical significance at $5 \%$ level.

\subsection{TESTING FOR A STRUCTURAL BREAK IN THE DATASET}

For direct comparison with Pozdena (2009), Granger causality results for the 1949-2007 period are provided in Panel (A) of Table 4.5. Note that when Pozdena's sub-period is used, the bidirectional result that he reports is also found in this study. Thus, it appears that the results for 
Granger causality may be somewhat dependent on the specific time period considered. Possible reasons for this difference are examined in the next section.

Table 4.5: Granger Causality: National Data-Structural Break at 1982 (1949-2007)

\begin{tabular}{|c|c|c|}
\hline \multirow{2}{*}{ Regression Name } & \multicolumn{2}{|c|}{ Probability $>$ Chi2 } \\
\hline & VMT causes Economy & Economy causes VMT \\
\hline \multicolumn{3}{|c|}{ Panel A: National Data (1949-2007) } \\
\hline VMT-GDP & $0.000 *$ & $0.000 *$ \\
\hline VMTPC-GDPPC & $0.000 *$ & $0.000 *$ \\
\hline VMT-PI & $0.000 *$ & $0.000 *$ \\
\hline VMTPC-PIPC & $0.000 *$ & $0.005^{*}$ \\
\hline \multicolumn{3}{|c|}{ Panel B: National Data (1949-1981) } \\
\hline VMT-GDP & $0.002 *$ & $0.000^{*}$ \\
\hline VMTPC-GDPPC & $0.000 *$ & $0.001 *$ \\
\hline VMT-PI & $0.001 *$ & $0.001 *$ \\
\hline VMTPC-PIPC & $0.001 *$ & $0.014^{*}$ \\
\hline \multicolumn{3}{|c|}{ Panel C: National Data (1982-2007) } \\
\hline VMT-GDP & 0.160 & 0.144 \\
\hline VMTPC-GDPPC & 0.221 & 0.202 \\
\hline VMT-PI & 0.411 & 0.172 \\
\hline VMTPC-PIPC & 0.455 & 0.242 \\
\hline \multicolumn{3}{|c|}{ Panel D: National Data (1982-2009) } \\
\hline VMT-GDP & $0.002 *$ & 0.120 \\
\hline VMTPC-GDPPC & $0.005^{*}$ & 0.216 \\
\hline VMT-PI & $0.002 *$ & 0.120 \\
\hline VMTPC-PIPC & $0.005^{*}$ & 0.216 \\
\hline
\end{tabular}

* Represents statistical significance at $5 \%$ level.

In the early part of the 20th century, the highway system was in its infancy. Following WWII, highway building accelerated, especially after the initiation of the interstate highway system in 1956 and its completion in the 1970s. The year 1982 is selected to subdivide the sample period for two reasons. First, it is reasonable to assume that most of the long-term location and development impacts from the investment in the interstate highway system were complete by that date. In comparing the periods pre- and post-1982, it can be seen that public road mileage grew at an annual percentage rate of .50 percent during the (1949-1981) time period, but only at a rate of .19 percent from (1982-2007). This dissimilarity, combined with lower real fuel prices, may have caused a larger induced travel demand impact in the earlier period. Since the more recent period is more directly relevant for prospective policymaking, it is important to know if there has been a change in the relationship between VMT and economic activity.

Second, the national level of aggregation may conceal important differences in the relationship between economic activity and VMT at the urban level, at which most policies are likely to be formulated and implemented. The TTI data used to explore the relationship in urban areas were only available on an annual basis from 1982 to the present.

A Chow test was used to test for a structural break in the post-WWII national data using the 1949-1981 and 1982-2007 as the sub-periods (see Hamilton, 1994 for a discussion of this technique). The resulting F-statistic $(2,55)$ of 74.07 suggests a significant improvement in the 
model's fit by splitting the sample at the year 1982 rather than pooling the data from 1929-2009 (Dougherty, 2007). This confirms the hypothesis of a structural change in the relationship between VMT and GDP at the national level in 1982.

This study re-examines Granger causality results for the pre- and post-1982 periods, and reports the results in Panels (B) and (C) of Table 4.5. As noted above, bidirectional causality is found between VMT and GDP for the whole 1949-2007 period. However, when the sample is split into the pre-and post-1982 periods, bidirectional result is found for the 1949-1982 period, but the post-1982 period finds no significant causal relationship. This suggests that VMT is not a major determinant of economic activity in the latter period.

As an interesting aside, Appendix $\mathrm{C}$ features a similar impulse response analysis to Pozdena's (2009) using the data and methodology from this paper for the periods 1929-2009 and 19822009. It finds economic activity to have a much smaller response to the exogenous shock of VMT, and shows the response to dissipate after only 10 years, contrasting the 20 -year significant long-run effect found by Pozdena (2009).

\subsection{IMPACT OF THE BUSINESS CYCLE ON THE VMT/ECONOMIC ACTIVITY RELATIONSHIP}

It should be noted that the results reported above are sensitive to the years included in the study. When the dataset is expanded to include 2008 and 2009 (years not included in Pozdena's 2009 study set), and the Granger causality results are updated, there is a surprising change. Now for the 1982-2009 period, there is significant unidirectional Granger causation flowing from VMT to economic activity (see Panel D in Table 4.5). Typically the addition of only two years would not be expected to completely change the significance of the Granger causation, but the two years added were both in the heart of an economic recession (known to be caused by the financial crisis and not an exogenous drop in VMT).

To examine the hypothesis that the causal relationship between VMT and economic activity might be affected by the business cycle, the National Bureau of Economic Research's (NBER's) dating for peaks and troughs in the business cycle between 1929 and 2009 is used to create two subsamples. Data for years are categorized as downturns if they occur during the time between a peak and a trough, and upturns if they occur during the time between a trough and a peak (The National Bureau of Economic Research, 2011). This analysis shows that during economic downturns VMT Granger causes economic activity or bidirectional causation is seen, but during economic upturns only economic activity Granger causes VMT (see Table 4.6).

This explains why the addition of the years 2008 and 2009, two economic downturn years, completely changed the output. It is also interesting to note that changes in VMT are often used by macroeconomic forecasters as one indicator of turning points in the business cycle - although every large macroeconomic cycle has generally accepted causes other than exogenous reductions in VMT.

Table 4.6: Granger Causality: National Data-Structural Break with Economic Downturns (1929-2009) 


\begin{tabular}{l|c|c}
\hline \multirow{2}{*}{ Regression Name } & \multicolumn{2}{c}{ Probability >Chi2 } \\
\cline { 2 - 3 } \multicolumn{1}{c}{ National Data: During Economic Downturn (n=16 out of the years from 1929-2009) } \\
\hline VMT-GDP & $0.002^{*}$ & 0.159 \\
\hline VMTPC-GDPPC & $0.005^{*}$ & 0.183 \\
\hline VMT-PI & $0.007^{*}$ & $0.003^{*}$ \\
\hline VMTPC-PIPC & $0.003^{*}$ & $0.026^{*}$ \\
\hline \multicolumn{2}{c}{ National Data: During Economic Upturn (n=62 out of the years from 1929-2009) } \\
\hline VMT-GDP & 0.113 & $0.000^{*}$ \\
\hline VMTPC-GDPPC & 0.140 & $0.000^{*}$ \\
\hline VMT-PI & 0.064 & $0.001^{*}$ \\
\hline VMTPC-PIPC & 0.217 & $0.002^{*}$ \\
\hline$*$ Represents statistical significance at 5\% level.
\end{tabular}

\subsection{URBAN AREA RESULTS (1982-2009)}

The same methodology that was applied to the national level dataset is used again for the urban area dataset. First data is aggregated over all 98 urban areas in the study and examines Granger results. The urban areas are then divided into the TTI urban size sub-groups to see if there is a difference in the relationship observed between VMT and economics activity depending on urban area size.

Table 4.7 displays the order of integration for the aggregate urban area variables and the population size groupings for the 1982-2009 dataset. It shows that VMT and VMTPC data are $\mathrm{I}(0)$ and thus regressed as levels, while all but one of the PI and PIPC variables are I(1) and are regressed as first differences. The one exception is the aggregate sample of 98 areas PI variable which was found to be $\mathrm{I}(2)$, and requires second differencing for stationarity.

As noted in the bottom of Tables 4.7 and 4.8, the urban area results were checked for robustness through the use of a more stringent 5-percent significance level for the augmented Dickey-Fuller test and through the incorporation of longer lag-lengths than HQIC's suggestion. The Probability $>C h i^{2}$ results for these robustness checks are not presented in the final Granger analysis in Table 4.9, but it should be noted that in no circumstance did VMT significantly Granger cause economic activity due to these changes. Yet, in the VMTPC-PIPC regression, economic activity did significantly Granger cause VMT when either longer lags were used or when a 5-percent significance level was used in the augmented Dickey-Fuller test. 
Table 4.7: Augmented Dickey-Fuller Test: 98 Urban Area's Data (1982-2009)

\begin{tabular}{l|c|c|c}
\hline \multirow{2}{*}{ Variable Name } & \multicolumn{2}{|c|}{ MacKinnon approximate p-value for Z $(\mathrm{t})=$} & \multirow{2}{*}{ Order of Integration } \\
\cline { 2 - 4 } & Logged Levels & Logged Differences & \\
\hline VMT & $0.0000^{*}$ & 0.9863 & $\mathrm{I}(0)$ \\
\hline VMTPC & $0.0000^{*}$ & 0.9352 & $\mathrm{I}(0)$ \\
\hline PI & 0.1573 & 0.1168 & $\mathrm{I}(2)$ \\
\hline VIPC*** & 0.1875 & $0.0612^{*}$ & $\mathrm{I}(1)$ \\
\hline VMTPC(lrg) & $0.0000^{*}$ & 0.8732 & $\mathrm{I}(0)$ \\
\hline VMTPC(med) & $0.0000^{*}$ & 0.9604 & $\mathrm{I}(0)$ \\
\hline VMTPC(sml) & $0.0000^{*}$ & 0.6215 & $\mathrm{I}(0)$ \\
\hline PIPC(vlg)*** & $0.0068^{*}$ & 0.3900 & $\mathrm{I}(0)$ \\
\hline PIPC(lrg)*** & 0.1571 & $0.0937^{*}$ & $\mathrm{I}(1)$ \\
\hline PIPC(med) & 0.1568 & $0.0962^{*}$ & $\mathrm{I}(1)$ \\
\hline PIPC(sml) & 0.1970 & $0.0251^{*}$ & $\mathrm{I}(1)$ \\
\hline
\end{tabular}

* Represents statistical significance at $10 \%$ level.

***Represents that the variables were additionally tested using the 5\% significance level for the ADF.

Since the VMT variables are stationary and do not share the same order of integration as the PI variables, they cannot be cointegrated. Hence, similarly to the national data, the standard VAR model can be applied here. The urban area tests indicate a two-year lag-length in every regression except VMTPC-PI, for which a third year was indicated and used (see Table 4.8). As before, when not all tests agree on lag-length the HQIC result is used.

Table 4.8: Lag-Length Selection Results: 98 Urban Area's Data (1982-2009)

\begin{tabular}{l|c}
\hline Regression Name & Suggested Lag-Length (Tests Abbreviations) \\
\hline VMT-PI & 2 lags* (LR, FPE, AIC, HQIC, and SBIC) \\
\hline VMTPC-PIPC** & 2 lags* (HQIC, SBIC) 4 lags (LR, FPE, AIC) \\
\hline VMT-PIPC & 2 lags* (LR, FPE, AIC, HQIC, and SBIC) \\
\hline VMTPC-PI & 3 lags* (LR, FPE, AIC, HQIC) 1 lag (SBIC) \\
\hline VMTPC(vlg)-PIPC(vlg) & 2 lags* (LR, FPE, AIC, HQIC, and SBIC) \\
\hline VMTPC(lrg)-PIPC(lrg) & 2 lags* (LR, FPE, AIC, HQIC, and SBIC) \\
\hline VMTPC(med)-PIPC(med)** & 2 lags* (FPE, AIC, HQIC) 4 lags (LR) 1 lag (SBIC) \\
\hline VMTPC(sml)-PIPC(sml)** & 2 lags* (HQIC, SBIC) 3 lags (LR, FPE, AIC) \\
\hline * Represents the lag-length selected for use in the VAR \\
$* *$ Represents that the variables were additionally tested using the longer lag-lengths.
\end{tabular}

Granger causation at the urban area level for medium, large and very large urban areas exhibits no significant causation in either direction, as shown in Table 4.9. While the aggregate urban VMTPC-PI regression shows economic activity to Granger causes VMT, and the small urban area grouping shows significant reverse causation flowing from VMT to the economy. Note that this table reports the 1982-2009 results which, for the national sample (see Table 4.5), actually exhibited reverse causation from VMT to economic activity. Thus, there seems to be a difference in the relationship between VMT and economic activity in larger urban areas as compared to smaller, more rural areas such as is seen in the national aggregation and the small urban area population grouping. 
Table 4.9: Granger Causality: 98 Urban Area's Data (1982-2009)

\begin{tabular}{l|c|c}
\hline \multirow{2}{*}{ Regression Name } & \multicolumn{2}{|c}{ Probability $>$ Chi2 } \\
\cline { 2 - 3 } & VMT causes Economy & Economy causes VMT \\
\hline VMT-PI & 0.524 & 0.357 \\
\hline VMTPC-PIPC*** & 0.116 & 0.101 \\
\hline VMT-PIPC $~$ & 0.151 & 0.454 \\
\hline VMTPC-PI & 0.111 & $0.002^{*}$ \\
\hline VMTPC(vlg)-PIPC(vlg)*** & 0.197 & 0.552 \\
\hline VMTPC(lrg)-PIPC(lrg)*** & 0.067 & 0.359 \\
\hline VMTPC(med)-PIPC(med)** & 0.368 & 0.125 \\
\hline VMTPC(sml)-PIPC(sml)** & $0.042^{*}$ & 0.462 \\
\hline
\end{tabular}

* Represents statistical significance at $5 \%$ level.

**Represents that the variables were additionally tested using the longer lag-lengths; resulting in no significant changes in the Granger causality findings.

***Represents that the variables were additionally tested using the 5\% significance level for the ADF; resulting in no significant changes in the Granger causality findings.

$\sim$ Represents that testing using a 5\% significance level for the ADF leads to PIPC uni-directionally significantly Granger causing VMTPC.

\subsection{INDIVIDUAL URBAN AREAS}

This section takes the 98 urban areas from the above analysis and separates them in order to study each area as an individual time-series. Table 4.10 shows Granger causation between VMTPC and PIPC in individual urban areas from 1982-2009. In looking at the 98 urban areas individually, it was found that only nine showed unidirectional reverse causation from VMTPC to PIPC at the 5-percent significance level. These areas are diverse both geographically and in terms of population size, making it hard to ascertain a pattern or theory as to how these nine areas differ from the other 89.

The areas that find reverse causation include Anchorage, Alaska; Birmingham-Hoover, Ala; Buffalo-Niagara Falls, N.Y.; Denver-Aurora-Broomfield, Colo.; McAllen, Texas; Miami-Fort Lauderdale-Pompano Beach, Fla; Poughkeepsie-Newburgh-Middletown, N.Y.; Provo, Utah; and Virginia Beach-Norfolk-Newport News, Va.-N.C. Additionally, significant bidirectional causation is found in Oklahoma City, Okla., Vancouver, Wash. and Portland-Hillsboro, Ore.

Table 4.10: Granger Causality: Individual Urban Areas (1982-2009)

\begin{tabular}{l|c|c}
\hline \multirow{2}{*}{ Regression Name } & \multicolumn{2}{|c}{ Probability $>$ Chi2 } \\
\cline { 2 - 3 } & VMTPC causes PIPC & PIPC causes VMTPC \\
\hline Akron, OH & 0.379 & 0.949 \\
\hline Albany-Schenectady-Troy, NY & 0.746 & 0.182 \\
\hline Albuquerque, NM & 0.288 & 0.903 \\
\hline Allentown-Bethlehem-Easton, PA-NJ & 0.749 & 0.177 \\
\hline Anchorage, AK & $0.000^{*}$ & 0.298 \\
\hline Atlanta-Sandy Springs-Marietta, GA & 0.068 & 0.498 \\
\hline Austin-Round Rock-San Marcos, TX & 0.257 & 0.243 \\
\hline Bakersfield-Delano, CA & 0.621 & 0.773 \\
\hline Baltimore-Towson, MD & 0.967 & 0.304 \\
\hline Baton Rouge LA & 0.224 & $0.041^{*}$ \\
\hline Beaumont-Port Arthur, TX & 0.095 & 0.308 \\
\hline
\end{tabular}




\begin{tabular}{|c|c|c|}
\hline Birmingham-Hoover, AL & $0.043^{*}$ & 0.440 \\
\hline Boise ID & 0.301 & 0.078 \\
\hline Boston-Cambridge-Quincy, MA-NH & 0.073 & 0.116 \\
\hline Boulder, $\mathrm{CO}$ & 0.220 & 0.282 \\
\hline Bridgeport-Stamford-Norwalk, CT & 0.128 & 0.332 \\
\hline Brownsville-Harlingen, TX & 0.121 & 0.256 \\
\hline Buffalo-Niagara Falls, NY & $0.013^{*}$ & 0.498 \\
\hline Cape Coral-Fort Myers, FL & 0.205 & $0.006^{*}$ \\
\hline Charleston-North Charleston-Summerville, SC & 0.878 & 0.573 \\
\hline Charlotte-Gastonia-Rock Hill, NC-SC & 0.247 & 0.155 \\
\hline Chicago-Joliet-Naperville, IL-IN-WI & 0.159 & 0.819 \\
\hline Cincinnati-Middletown, OH-KY-IN & 0.723 & 0.388 \\
\hline Cleveland-Elyria-Mentor, $\mathrm{OH}$ & 0.392 & $0.045^{*}$ \\
\hline Colorado Springs, CO & 0.964 & 0.085 \\
\hline Columbia, SC & 0.531 & 0.324 \\
\hline Columbus, $\mathrm{OH}$ & 0.663 & 0.354 \\
\hline Corpus Christi, TX & 0.068 & 0.737 \\
\hline Dallas-Fort Worth-Arlington, TX & 0.486 & 0.189 \\
\hline Dayton, $\mathrm{OH}$ & 0.312 & 0.152 \\
\hline Denver-Aurora-Broomfield, CO & $0.006^{*}$ & 0.368 \\
\hline Detroit-Warren-Livonia, MI & 0.116 & 0.497 \\
\hline El Paso, TX & 0.063 & 0.989 \\
\hline Eugene-Springfield, OR & 0.510 & 0.385 \\
\hline Fresno, CA & 0.445 & 0.583 \\
\hline Grand Rapids-Wyoming, MI & 0.612 & 0.136 \\
\hline Greensboro NC & 0.539 & 0.817 \\
\hline Hartford-West Hartford-East Hartford, CT & 0.798 & 0.090 \\
\hline Honolulu, HI & 0.938 & 0.072 \\
\hline Houston-Sugar Land-Baytown, TX & 0.889 & 0.531 \\
\hline Indianapolis-Carmel, IN & 0.292 & 0.992 \\
\hline Jackson MS & 0.425 & 0.788 \\
\hline Jacksonville, FL & 0.322 & 0.832 \\
\hline Kansas City, MO-KS & 0.966 & 0.083 \\
\hline Knoxville, TN & 0.773 & 0.677 \\
\hline Laredo, TX & 0.199 & 0.146 \\
\hline Las Vegas-Paradise, NV & 0.060 & 0.288 \\
\hline Little Rock-North Little Rock-Conway, AR & 0.063 & 0.271 \\
\hline Los Angeles-Long Beach-Santa Ana, CA & 0.987 & 0.967 \\
\hline Louisville-Jefferson County, KY-IN & 0.242 & 0.519 \\
\hline Madison, WI & 0.192 & $0.017 *$ \\
\hline McAllen, TX & $0.003^{*}$ & 0.756 \\
\hline Memphis, TN-MS-AR & 0.303 & 0.064 \\
\hline Miami-Fort Lauderdale-Pompano Beach, FL & $0.000^{*}$ & 0.655 \\
\hline Milwaukee-Waukesha-West Allis, WI & 0.894 & 0.524 \\
\hline Minneapolis-St. Paul-Bloomington, MN-WI & 0.084 & 0.646 \\
\hline Nashville-Davidson-Murfreesboro-Franklin, TN & 0.593 & 0.942 \\
\hline New Haven-Milford, CT & 0.093 & 0.353 \\
\hline New Orleans-Metairie-Kenner, LA & 0.247 & $0.000^{*}$ \\
\hline New York-Northern New Jersey-Long Island, NY-NJ & 0.086 & $0.002 *$ \\
\hline Oklahoma City, OK & $0.017^{*}$ & $0.031^{*}$ \\
\hline Omaha-Council Bluffs, NE-IA & 0.731 & 0.597 \\
\hline Orlando-Kissimmee-Sanford, FL & 0.583 & 0.684 \\
\hline
\end{tabular}




\begin{tabular}{|c|c|c|}
\hline Oxnard-Thousand Oaks-Ventura, CA & 0.100 & 0.069 \\
\hline Pensacola-Ferry Pass-Brent, FL & 0.543 & 0.636 \\
\hline Philadelphia-Camden-Wilmington, PA-NJ-DE-MD & 0.435 & 0.828 \\
\hline Phoenix-Mesa-Glendale, AZ & 0.956 & 0.476 \\
\hline Pittsburgh, PA & 0.187 & 0.217 \\
\hline Portland-Vancouver-Hillsboro, OR-WA & $0.029^{*}$ & $0.029 *$ \\
\hline Poughkeepsie-Newburgh-Middletown, NY & $0.000^{*}$ & 0.983 \\
\hline Providence-New Bedford-Fall River, RI-MA & 0.697 & 0.117 \\
\hline Provo UT & $0.022^{*}$ & 0.395 \\
\hline Raleigh-Cary, $\mathrm{NC}$ & 0.259 & 0.131 \\
\hline Richmond, VA & 0.820 & 0.511 \\
\hline Riverside-San Bernardino-Ontario, CA & 0.826 & 0.869 \\
\hline Rochester, NY & 0.262 & $0.019 *$ \\
\hline Sacramento-Arden-Arcade-Roseville, CA & 0.629 & 0.219 \\
\hline Salem, OR & 0.491 & $0.009^{*}$ \\
\hline Salt Lake City, UT & 0.258 & 0.323 \\
\hline San Antonio-New Braunfels, TX & 0.473 & 0.770 \\
\hline San Diego-Carlsbad-San Marcos, CA & 0.311 & 0.237 \\
\hline San Francisco-Oakland-Fremont, CA & 0.558 & 0.292 \\
\hline San Jose-Sunnyvale-Santa Clara, CA & 0.052 & 0.964 \\
\hline Sarasota-Bradenton FL & 0.206 & 0.640 \\
\hline Seattle-Tacoma-Bellevue, WA & 0.910 & 0.756 \\
\hline Spokane, WA & 0.337 & 0.173 \\
\hline Springfield, MA & 0.479 & 0.877 \\
\hline St. Louis, MO-IL & 0.551 & $0.022 *$ \\
\hline Stockton CA & 0.381 & 0.090 \\
\hline Tampa-St. Petersburg-Clearwater, FL & 0.222 & 0.322 \\
\hline Toledo, $\mathrm{OH}$ & 0.301 & 0.708 \\
\hline Tucson, AZ & 0.371 & 0.776 \\
\hline Tulsa, OK & 0.801 & 0.329 \\
\hline Virginia Beach-Norfolk-Newport News, VA-NC & $0.012 *$ & 0.364 \\
\hline Washington-Arlington-Alexandria, DC-VA-MD-WV & 0.626 & 0.123 \\
\hline Wichita, KS & 0.888 & 0.745 \\
\hline Winston-Salem NC & 0.242 & 0.371 \\
\hline Worcester MA & 0.861 & 0.442 \\
\hline Urban Areas (Observations per panel) & $98(25)$ & $98(25)$ \\
\hline Count of Significant Urban Areas at the 5\% level & 11 & 11 \\
\hline Percent of Areas that are Significant at the 5\% level & $11.22 \%$ & $11.22 \%$ \\
\hline
\end{tabular}

* Represents statistical significance at 5\% level (H1: Granger causation).

These reported results for Granger causality do not control for characteristics of individual urban areas which may cause VMTPC to vary. For instance, an urban area where drivers have transit as a substitute for driving may have lower VMTPC than other areas where there is no viable transit alternative. Accordingly, the observed relationship between VMTPC and PIPC may differ across urban areas and thus the impact of policies to reduce VMTPC may differ across urban areas. To control for interurban differences, the following section explores determinants of VMTPC. We then re-estimate the Granger causality results controlling for differences in characteristics across urban areas. 


\subsection{DERIVED DEMAND}

\subsection{INTRODUCTION}

The Granger causality results make it clear that there is significant variation in the findings depending on the areas analyzed. For example, during the time span from 1982-2009 reverse causation is found at the national level and in the small, urban population size grouping, but is not found for the sample of 98 urban areas, the very large, large or medium-sized urban population-size groupings or for a strong majority of the individual urban areas. If one takes into consideration that the national sample includes rural and urban areas, it becomes apparent that only the less densely populated regions are finding reverse causation.

Thus, further exploration of the determinants of VMT in various urban areas is necessary for a better understanding of how VMT may depend on other factors, such as the availability of alternative transportation modes, fuel price, road infrastructure, population density and employment levels in certain industries. The evaluation of such factors should reinforce the deduction that VMT could be causally related to economic activity in less populated areas due to the prevalence of these factors in smaller areas.

If VMT-reduction policies are implemented in areas where VMT cannot be substituted with other modes, then overall mobility would be reduced, leading to negative economic ramifications. Alternatively, the same policies in larger urban areas that feature more alternative modes of transportation might not have the same influence. The purpose of the following chapter on VMT demand is to help shed light on this and other VMT relationships at a more micro level.

\subsubsection{Variable Selection and Expected Relationship with VMT}

Prior to delving into the results of these models, reasoning is established for the presence of each independent variable included in the model. Independent variables included should have a direct effect on the demand for average daily freeway and arterial VMT per capita in urban areas. The dependent variable of interest in this paper is VMT, but most studies use VMT per capita (VMTPC) (Noland and Cowart, 2000; Fulton et al., 2000).

Economic theory suggests some basic determinants of demand for a product: price, income and population (when more than one consumer is considered). Average annual state gasoline prices in real 2005 dollars are used to represent the price or marginal cost of driving. Although there are certainly other components that attribute to VMT's price, such as insurance, wear and tear on the vehicle, driving time, etc., the price of gasoline is a large component and the data is easily available here. Additionally, the real fuel cost $(R F C)$ has been used in other studies as a proxy for the price of driving (McMullen et al., 2009; Fulton et al., 2000; and Noland, 2001). Price elasticities of demand for driving are expected by economic theory to be negative and are found in other studies to range from -0.17 to -0.05 in the short run, and -0.63 to -0.10 in the long run (Goodwin, Dargay and Hanly, 2004). 
Since VMT is usually considered to be a normal good, higher incomes are expected to result in more driving and thus VMT, ceteris paribus. Accordingly, personal income per capita (PIPC) is included as an indicator of the average incomes in urban areas. Positive income elasticities of demand are found consistently in the literature and range from 0.05 to 0.62 in the short run, and 0.12 to 1.47 in the long run (Goodwin, Dargay and Hanly, 2004).

Another possible determinant of VMTPC in urban areas is population density; as populations spread out, more driving is expected. Population density is expected to be correlated to VMTPC, as various papers which analyze smart growth, urban growth boundaries, and mixed development demonstrate that denser cities allow for shorter routes, more one-stop shopping, and more walking and biking options, thereby reducing the need for vehicle travel (Winkelman, Bishins and Kooshian, 2009; Frank and Pivo, 1995; and Litman, 2010).

To incorporate VMT substitutes into the model, transit passenger miles traveled per capita (PMTPC) is included as an explanatory variable and is anticipated to have a negative elasticity, as found in similar studies (Pushkarev and Zupan, 1980; Holtzclaw, 1991). Transit ridership in an urban area should be correlated with lower VMT levels as transit availability presents the consumer an alternative to driving.

This study additionally incorporates industry employment mix variables, adding a new wrinkle to the typical VMT-derived demand model. These variables indicate the percent of an urban area's economy that is employed in certain industries, allowing for direct evaluation of the VMT intensity of industries during the production, distribution and sales processes. For instance, it is plausible that an industry sector like construction, which requires large amounts of labor and supply movement, may be more VMT-intense than an industry sector such as finance, which allows for money, advice and services to take place either over the phone, fax or Internet rather than driving.

Finally, the most challenging variable to consider is that relating to the highway investment in an urban area, as usually measured by lane miles (LM) or lane miles per capita (LMPC). The literature suggests that LM is not truly exogenous in respect to VMT or VMTPC. It has been demonstrated that increases in VMT increase the demand for road capacity and can lead to more lane miles being built. Moreover, increases in lane miles of highway will reduce the cost of driving and induce more VMT, leading to a significant simultaneity bias (Noland, 2001; Fulton et al., 2000; Goodwin, 1996; and Pells, 1989).

\subsubsection{Multicollinearity Test}

To reduce multicollinearity it was decided to define variables in per capita terms, notably PIPC, LMPC, and PMTPC. Note that industry employment variables are defined as ratios of employment in that industry to total employment. These changes help reduce multicollinearity from the otherwise large, consistent growth trend and cross-sectional collinearity. Finally, the exclusion of population as an independent variable further eradicates excessive collinearity.

The "Collin" command in the Stata 11.1 (64-bit) Data Analysis and Statistical Software Program computes several collinearity diagnostic measures, including variance inflation factor (VIF), tolerance, eigenvalues, condition index and R-squared. In the VIF and condition number 
tests any results greater than 10 are interpreted to contain significant collinearity. The final arrangement of variables finds no VIF greater than 10, a mean VIF of only 1.75, and a condition number of 3.62. Therefore, the regression does not suffer from collinearity when specified in this manner.

The final set of explanatory variables described above is listed and defined here; these variables will make up the $\mathrm{X}_{\mathrm{it}}^{\mathrm{k}}$ matrix in the following model specification equation:

- $\quad \mathrm{LMPC}_{\mathrm{it}}$, freeway and arterial lane miles per capita for urban area $i$ in year $t$;

- $\quad$ PIPC $_{\mathrm{it}}$, personal income per capita in real 2005 dollars for the relevant MSA $i$ in year $t$;

- $\quad \mathrm{RFC}_{\mathrm{it}}$, state average price of fuel in real 2005 dollars for urban area $i$ in year $t$;

- $\quad$ PMTPC $_{\mathrm{it}}$, transit passenger miles traveled per capita for urban area $i$ in year $t$;

- $\quad$ DENSITY $_{\mathrm{it}}$, the number of residents per square mile of urban area $i$ in year $t$;

- $\mathrm{CON}_{\mathrm{it}}, \mathrm{MANU}_{\mathrm{it}}, \mathrm{FIN}_{\mathrm{it}}, \mathrm{WHOLE}_{\mathrm{it}}, \mathrm{RETAIL}_{\mathrm{it}}$ (industry employment variables), the percent of total employment that resides in an industry in the relevant MSA $i$ and year $t$;

- $\mathrm{PUB}_{\text {it }}$, the ratio of public employees to private sector employees in MSA $i$ in year $t$.

\subsection{METHODOLOGY}

\subsubsection{Standard OLS Model}

The econometric specification for the VMTPC equation is estimated here as:

$$
\log \left(V M T P C_{i t}\right)=\mathrm{c}+\alpha_{i}+\beta_{t}+\sum_{k} \lambda^{k} * \log \left(X_{i t}^{k}\right)+\varepsilon_{i t}
$$

Where:

- $\quad V M T P C_{i t}$ is the average daily freeway and arterial vehicle miles traveled per capita for urban area $i$ in year $t$;

- $\quad \mathrm{c}$ is a constant term for the entire sample;

- $\quad \alpha_{i}$ is the group specific fixed effect for urban area $i$;

- $\quad \beta_{t}$ is the time specific fixed effect for year $t$;

- $\lambda^{k}$ is the coefficient of the $k^{\text {th }}$ explanatory variable;

- $\quad X_{i t}^{k}$ is the value of explanatory variable $k$ for urban area $i$ and year $t$.

- $\varepsilon_{i t}$ is the error term of a random variable for urban area $i$ in year $t$, assumed to be normally distributed with mean zero. 
The model transforms all variables (except for the fixed-effect dummies) into natural logarithms, making the coefficients easily interpreted as elasticities and to help avoid heteroskedasticity. Note that the group-specific fixed effect $\alpha_{i}$ can be defined as regional grouping $\alpha_{i}$, or TTI population size grouping $\alpha_{i}$ instead of urban area $\alpha_{i}$ (see Appendix A for categorical definitions and a list of urban areas in each group). These different group-specific fixed effects allow for interpretation of an important relationships between VMTPC and region or population size, but provide less total information because they incorporate a smaller number of less-specific dummy variables.

\subsubsection{Distributed Lag Model}

The distributed lag model, as used in Noland and Cowart (2000), is written as:

$$
\log \left(V M T P C_{i t}\right)=\mathrm{c}+\alpha_{i}+\beta_{t}+\gamma * \log \left(V M T P C_{i t-1}\right)+\sum_{k} \lambda^{k} * \log \left(X_{i t}^{k}\right)+\varepsilon_{i t}
$$

Where all specifications are identical to the previous fixed-effects model, except for the inclusion of $V M T P C_{i t-1}$, the one-year lagged value of average daily freeway and arterial vehicle miles traveled per capita for urban area $i$ in year $t-1$, and that $\mathrm{T}=27$ for the distributed lag model, instead of $\mathrm{T}=28$ as seen previously.

The distributed lag model differs from the basic model by incorporating a lagged value of the dependent variable $(V M T P C)$ on the right-hand side of the equation. This methodology allows for the calculation of long-term and short-term elasticities, where the long-term elasticities are

calculated as $\varepsilon=\frac{\lambda}{1-\gamma}$, where $\lambda$ are the short-run elasticities (found in the regression's coefficients), and $\gamma$ is the coefficient of the one year lag of VMTPC. The model assumes an exponential lag structure that shows short-run impacts to be greatest and to diminish exponentially over time (Noland and Cowart, 2000).

\subsubsection{Two-Stage Least Squares Model}

To deal with the endogeneity problem noted above for lane miles (LMPC), a two-stage least squares (2SLS) model is used, requiring the selection of an appropriate instrumental variable. Following Noland and Cowart's (2000) methodology and available data, urban land area (ULA) is selected as the instrument of choice. The first and second stages of the 2SLS model are written as:

$$
\begin{aligned}
& \log \left(L M P C_{i t}\right)=\mathrm{c}+\alpha_{i}+\beta_{t}+\sum_{k} \lambda^{k} * \log \left(X_{i t}^{k}\right)+\gamma^{*} \log \left(U L A_{i t}\right)+\varepsilon_{i t} \\
& \log \left(V_{M T P C_{i t}}\right)=\mathrm{c}+\alpha_{i}+\beta_{t}+\sum_{k} \lambda^{k} * \log \left(X_{i t}^{k}\right)+\gamma^{*} \log (\overline{L M P C})_{i t}+\varepsilon_{i t}
\end{aligned}
$$

Where all specifications are identical to the model already specified expect that $X_{i t}^{k}$ no longer includes the endogenous variable, $(L M P C), U L A_{i t}$ is the square miles of land area within urban area $i$ in year $t$, and $\overline{L M P C}_{i t}$ is the predicted estimate of $L M P C$ within urban area $i$ in year $t$ taken from the first-stage regression. Again, all variables are given as natural logarithms. 
As is expressed in the above set of equations, to incorporate 2SLS into the model, urban land area $(U L A)$ is added to the first stage, which predicts $L M P C$ using all available instruments. Then, the predicted estimate $\overline{L M P C}_{i t}$ is applied to the VMTPC equation in the second stage, removing the simultaneity bias.

An appropriate instrumental variable must be both relevant, in that it is significantly related to the endogenous variable being instrumented, but also exogenous in that it is not correlated with the error term in the explanatory equation. Exogeneity ensures that the instrument's only influence on the dependent variable is through its effect on the endogenous variable and that it should not be an independent variable of the model in its own right (for further details on 2SLS and instrumental variables, see Greene, 2008).

Econometric tests are performed to see if the model supports the use of $U L A$ as an instrument. First, a Durbin-Wu-Hausman test for endogeneity of $L M P C$ is performed. Next, tests are applied to determine the relevance of the instrument. Finally, the exogeneity of the instrument itself, $U L A$, is examined.

A Durbin-Wu-Hausman test for endogeneity uses the null hypothesis that the possible endogenous regressor, $L M P C$, is exogenous. It compares estimates from the corresponding 2SLS and OLS regressions to see if differences between the two estimates are statistically significant. With ULA as the instrument in the 2SLS model, the Durban-Wu-Hausman test gave a statistically significant $C h i^{2}$ (8) test statistic equal to 38.64. Thus, the null hypothesis is rejected, suggesting that $L M P C$ is endogenous, indicating the use of a method such as 2 SLS.

Next, a highly significant negative t-statistics is found for $U L A$ in the first stage of the 2SLS, implying that $U L A$ is sufficiently related to $L M P C$ to make it "relevant" and appropriate for use in the 2SLS. Additionally, ULA has a fairly low correlation with VMTPC of 0.32 , which indicates its exogeneity and that it does not need to be included in the model in its own right. Hence, $U L A$ is used as an instrument because, through a survey of the literature on this simultaneous relationship between lane miles and vehicle miles traveled, no clearly exogenous instrument is found to be more relevant than urban land area ${ }^{1}$.

\subsection{DATA}

From the introduction and methodology of this chapter it is clear that a much more in-depth dataset is required for derivation of VMT demand than in the Granger causality analysis. This chapter uses the same data sources as the urban sample for the Granger causality analysis. However, only 87 of the 98 urban areas in the Granger sample are used because some areas were not included in the $2007 \mathrm{UMR}$, and hence did not have annual data on two key variables needed in this analysis, urban land area (ULA) and population density (DENSITY). The data used in this chapter is considered "panel data," as it incorporates both time-series and cross-sectional variation, whereas all previous data in this paper were purely time-series.

\footnotetext{
${ }^{1}$ Previous works have noted difficulty in finding an appropriate instrumental variable, saying "all the variables that may correlate with lane miles also tend to be correlated with VMT" (Noland, 2001). Hansen and Huang (1997) also were unable to locate an appropriate instrument for their analysis.
} 
The panel data displays every urban area's specific DENSITY, LMPC, RFC and PMTPC, which are all from the 2010 UMR (Texas Transportation Institute, 2011). The source for PIPC and the industry employment statistics is BEA for the 87 associated MSAs (U.S. Department of Commerce, 2011).

Table 5.1 present summary statistics for the variables used in this chapter. These statistics do not exactly match those found in Table 3.2 because this table only includes data for 87 of the 98 urban areas used previously. On average between 1982 and 2009, an individual in these 87 urban areas drove over 16 miles a day on freeways and arterial roads, was a passenger on 124 miles of public transit annually, earned an average annual income of nearly \$32,000 in real 2005 dollars, and paid nearly \$2 a gallon for gas in real 2005 dollars.

Table 5.1: Sample of 87 Urban Area's Summary Statistics (1982-2009)

\begin{tabular}{|c|c|c|c|c|}
\hline Variable Name & Mean & Std. Dev. & Min & Max \\
\hline Vehicle Miles Traveled (VMT) & $25,450,000$ & $34,580,000$ & 550,000 & $265,290,000$ \\
\hline Vehicle Miles Traveled Per Capita (VMTPC) & 16.44 & 3.83 & 5.50 & 29.51 \\
\hline Urban Area Population (POPu) & $1,572,530$ & $2,369,525$ & 95,000 & $18,768,000$ \\
\hline Population Density (DENSITY) & 2,244 & 898 & 989 & 5,767 \\
\hline Urban Land Area (ULA) & 643 & 659 & 25 & 4,810 \\
\hline Lane Miles (LM) & $3,450,211$ & $4,125,103$ & 175,000 & $27,020,000$ \\
\hline Lane Miles Per Capita (LMPC) & 2.52 & 0.61 & 1.21 & 5.03 \\
\hline Real Fuel Cost (RFC) & $\$ 1.96$ & $\$ 0.54$ & $\$ 1.11$ & $\$ 3.72$ \\
\hline Transit Pass. Miles of Travel $(000,000)$ (PMT) & 457 & 1,905 & 1.40 & 21,699 \\
\hline Transit Pass. Miles of Travel Per Capita (PMTPC) & 124.30 & 148.72 & 1.97 & 1163.95 \\
\hline Personal Income $(000,000)(\mathrm{PI})^{*}$ & $\$ 65,373$ & $\$ 99,722$ & $\$ 1,364$ & $\$ 958,964$ \\
\hline Personal Income Per Capita (PIPC)* & $\$ 31,613$ & $\$ 7,014$ & $\$ 11,822$ & $\$ 74,954$ \\
\hline MSA Population* (POPm) & $1,883,582$ & $2,502,117$ & 111,106 & $19,069,796$ \\
\hline Public Private Employment Ratio (PUB)* & $18.66 \%$ & $7.56 \%$ & $8.24 \%$ & $58.71 \%$ \\
\hline Percent Finance-Ins.-Real Estate Employment(FIN)* & $8.34 \%$ & $1.87 \%$ & $0.34 \%$ & $17.76 \%$ \\
\hline Percent Construction Employment $(\mathrm{CON})^{*}$ & $5.68 \%$ & $1.36 \%$ & $2.95 \%$ & $14.85 \%$ \\
\hline Percent Manufacturing Employment (MANU)* & $10.91 \%$ & $5.40 \%$ & $1.01 \%$ & $32.06 \%$ \\
\hline Percent Wholesale Employment (WHOLE)* & $4.51 \%$ & $1.21 \%$ & $1.83 \%$ & $9.26 \%$ \\
\hline Percent Retail Employment (RETAIL)* & $14.88 \%$ & $3.15 \%$ & $7.46 \%$ & $27.54 \%$ \\
\hline
\end{tabular}

*Represents that statistics are from MSAs and not UAs

Only the percent industry employment variables have missing data. Number of missing observations is: FinanceInsurance-Real Estate $=8$, Construction=45, Manufacturing=14, Wholesale $=85$ and Retail $=9$.

\section{$5.4 \quad$ RESULTS}

The inclusion of "two-way' fixed effects, which applies dummy variables to both an observation's group (urban area) and time period (year), provides static coefficient estimates for the entire sample, while dynamically shifting the constant term for each observation. This allows unmeasured or unknown cross-sectional (urban area) and time-series (year) factors to be 
explained through the fixed effects' coefficients, and reduces any remaining bias due to omitted variables that are inevitably left out of the model (Dougherty, 2007).

The fixed effect coefficients in this study control for potential omitted variables, such as the number of women in the workforce, car ownership, population growth, climate and the existence of driving alternatives not measured by the $P M T P C$ transit variable such as walking/biking paths, telecommuting, along with other unknown or unmeasured factors.

F-statistics are used to test the significance of the fixed effects, with the null hypothesis that the fixed effects are not jointly significantly related to $V M T P C$. First a comparison is made between a standard OLS model and a model with group-specific effects, resulting in a significant Fstatistic of $F(86,2267)=104.72$. Then, the model with only the group-specific effects is compared to a model with group and time-specific or "two-way" effects fixed model, resulting in a significant $F(27,2240)=23.94$. Both results allow for a rejection of the null hypothesis and support the use of "two-way" fixed effects in the model estimation (Greene, 2008).

\subsubsection{Standard OLS Results}

Table 5.2 displays the model with four sets of different industry employment variable specifications, ordered in columns from (A) to (D). Column (A) only includes the public-private employment ratio $(P U B)$ and no other industry sector variables. This specification gives a large significantly positive coefficient and produces the largest R-squared of the four regressions, but fails to provide in-depth examination of specific industries effects on VMTPC. Column (B) comprises all five of the percent industry employment variables. Of these, only construction $(C O N)$ is positively significantly correlated with $V M T P C$, and only manufacturing $(M A N U)$ is negatively significant. Column $(C)$ omits the insignificant industry employment variables found in Column (B), leaving only construction and manufacturing; doing this increases the R-squared by about one percent.

Column (D) integrates percent wholesale employment (WHOLE) in the place of $M A N U$, and has a much larger R-squared than Column (C). Although, WHOLE takes on the expected sign, it does not become significant until the simultaneity bias is removed, as shown in the 2SLS model results.

$L M P C, P I P C, R F C$ and $P M T P C$ all give expected signs and are statistically significant at the five percent level in all four columns of Table 5.2. Whereas, the DENSITY coefficient sign varies between regressions and is not found to be statistically significant in any of the four columns, this is likely attributable to DENSITY's strong correlation with LMPC, which is known to feature a strong simultaneity bias.

\footnotetext{
2 Two models are considered in setting up the panel data: random effects and fixed effects. A rejection of the Hausman test confirmed that a random effects estimator is not consistent with the fixed effects coefficients, and is thus not efficient (Dougherty, 2007). Additionally, the Breusch and Pagan Lagrangian Multiplier test for random effects confirmed that the model does not meet a primary assumption of a random effects model because the variance of error term " $u$ " does not equal zero (Breusch and Pagan, 1980). Thus, a fixed effects model was selected, similarly to Noland (2001), Fulton et al. (2000) and other papers in the literature on VMT's derived demand.
} 
Table 5.2: Fixed Effects Model with Varying Employment Mix Variables "Dependent Variable: VMTPC" (1982-2009)

\begin{tabular}{|c|c|c|c|c|}
\hline Variable Name & $\begin{array}{c}\text { (A) } \\
\text { UA \& Year } \\
\text { Effects }\end{array}$ & $\begin{array}{c}\text { (B) } \\
\text { UA \& Year } \\
\text { Effects }\end{array}$ & $\begin{array}{c}\text { (C) } \\
\text { UA \& Year } \\
\text { Effects }\end{array}$ & $\begin{array}{c}\text { !(D) } \\
\text { UA \& Year } \\
\text { Effects }\end{array}$ \\
\hline Lane Miles Per Capita (LMPC) & $\begin{array}{l}.4902 * \\
(27.47) \\
\end{array}$ & $\begin{array}{l}.4865 * \\
(27.88) \\
\end{array}$ & $\begin{array}{l}.4941 * \\
(29.15) \\
\end{array}$ & $\begin{array}{l}.4994 * \\
(28.10) \\
\end{array}$ \\
\hline Personal Income Per Capita (PIPC) & $\begin{array}{l}.3127^{*} \\
(9.68)\end{array}$ & $\begin{array}{l}.1358^{*} \\
(3.97)\end{array}$ & $\begin{array}{l}.1606^{*} \\
(4.82)\end{array}$ & $\begin{array}{l}.2487^{*} \\
(7.38)\end{array}$ \\
\hline Population Density (DENSITY) & $\begin{array}{l}-.0087 \\
(-0.55) \\
\end{array}$ & $\begin{array}{l}.0198 \\
(1.26) \\
\end{array}$ & $\begin{array}{l}.0162 \\
(1.05) \\
\end{array}$ & $\begin{array}{l}-.0152 \\
(-0.96) \\
\end{array}$ \\
\hline Real Fuel Cost (RFC) & $\begin{array}{l}-.1231 * \\
(-3.96) \\
\end{array}$ & $\begin{array}{l}-.1431 * \\
(-4.67) \\
\end{array}$ & $\begin{array}{l}-.1351 * \\
(-4.46)\end{array}$ & $\begin{array}{l}-.1263 * \\
(-4.02) \\
\end{array}$ \\
\hline Transit Pass. Miles Travel Per Capita (PMTPC) & $\begin{array}{c}-.0193 * \\
(-4.08)\end{array}$ & $\begin{array}{l}-.0189 * \\
(-4.04)\end{array}$ & $\begin{array}{l}-.0194 * \\
(-4.23)\end{array}$ & $\begin{array}{l}-.0176^{*} \\
(-3.70)\end{array}$ \\
\hline Public Private Employment Ratio (PUB) & $\begin{array}{c}.0663^{*} \\
(3.49) \\
\end{array}$ & & & \\
\hline Percent Finance-Insure-Real Estate Employment(FIN) & & $\begin{array}{l}.0074 \\
(0.70) \\
\end{array}$ & & \\
\hline Percent Construction Employment (CON) & & $\begin{array}{l}.0697^{*} \\
(4.59)\end{array}$ & $\begin{array}{l}.0607^{*} \\
(4.09)\end{array}$ & $\begin{array}{l}.0338 * \\
(2.22)\end{array}$ \\
\hline Percent Manufacturing Employment (MANU) & & $\begin{array}{l}-.1636^{*} \\
(-12.19)\end{array}$ & $\begin{array}{l}-.1659 * \\
(-12.72)\end{array}$ & \\
\hline Percent Wholesale Employment (WHOLE) & & $\begin{array}{l}-.0113 \\
(-0.63) \\
\end{array}$ & & $\begin{array}{l}-.0061 \\
(-0.33) \\
\end{array}$ \\
\hline Percent Retail Employment (RETAIL) & & $\begin{array}{l}-.0521 \\
(-1.43) \\
\end{array}$ & & \\
\hline Constant & $\begin{array}{c}-.6953 * \\
(-1.98) \\
\end{array}$ & $\begin{array}{l}.5619 \\
(1.45) \\
\end{array}$ & $\begin{array}{l}.4066 \\
(1.08) \\
\end{array}$ & $\begin{array}{l}-.0340 \\
(-0.09) \\
\end{array}$ \\
\hline Number of Urban Areas & 87 & 87 & 87 & 87 \\
\hline Number of Years & 28 & 28 & 28 & 28 \\
\hline Number of Total Obs. & 2436 & $2344 * *$ & $2422 * *$ & $2361 * *$ \\
\hline R-squared & 0.5577 & 0.3958 & 0.4055 & 0.5529 \\
\hline
\end{tabular}

* Represents statistical significance at the 5\% level.

**Represents smaller R-squared due to missing observations from BEA employment statistics.

! Represents the optimal specification; to which other models can be compared.

All regressions in Table 5.3 include the same independent variables as Column (D) of Table 5.2, but with varying results for alternative ways of grouping and defining the fixed effects. For instance, Column (B) uses regional groupings for urban areas in the eastern, central and western part of the U.S., so that western is omitted as the control group (see Appendix A for a list of urban areas in each group). The negative coefficients on both the central and eastern regional dummies indicate that ceteris paribus, $V M T P C$ is higher the more western the urban area regional grouping. This could be due to the smaller population density of western urban areas or larger land areas and distances between major cities along with a number of other regional factors (see discussion of possible omitted variables on pg. 30). 
Table 5.3: Fixed Effects Model with Varying Group Effects “Dependent Variable: VMTPC" (1982-2009)

\begin{tabular}{|c|c|c|c|c|}
\hline Variable Name & $\begin{array}{c}\text { (A) } \\
\text { No Group } \\
\text { Effects }\end{array}$ & $\begin{array}{c}\text { (B) } \\
\text { Regional \& } \\
\text { Year Effects }\end{array}$ & $\begin{array}{c}(\mathrm{C}) \\
\text { Pop. Size \& } \\
\text { Year Effects }\end{array}$ & $\begin{array}{c}\text { !(D) } \\
\text { UA \& Year } \\
\text { Effects }\end{array}$ \\
\hline Lane Miles Per Capita (LMPC) & $\begin{array}{c}4974^{*} \\
(28.37) \\
\end{array}$ & $\begin{array}{c}.4709 * \\
(27.27) \\
\end{array}$ & $\begin{array}{l}.5065^{*} \\
(29.67) \\
\end{array}$ & $\begin{array}{l}4994^{*} \\
(28.10) \\
\end{array}$ \\
\hline Personal Income Per Capita (PIPC) & $\begin{array}{l}.5363^{*} \\
(28.25) \\
\end{array}$ & $\begin{array}{l}.5413 * \\
(28.15) \\
\end{array}$ & $\begin{array}{c}.4351 * \\
(21.60) \\
\end{array}$ & $\begin{array}{l}.2487^{*} \\
(7.38)\end{array}$ \\
\hline Population Density (DENSITY) & $\begin{array}{l}.0408^{*} \\
(3.40)\end{array}$ & $\begin{array}{l}-.0120 \\
(-0.94)\end{array}$ & $\begin{array}{l}.0084^{*} \\
(0.70)\end{array}$ & $\begin{array}{l}-.0152 \\
(-0.96)\end{array}$ \\
\hline Real Fuel Cost (RFC) & $\begin{array}{c}-.1681^{*} \\
(-3.32)\end{array}$ & $\begin{array}{c}-.4547^{*} \\
(-8.00)\end{array}$ & $\begin{array}{c}-.0450 * \\
(-0.88)\end{array}$ & $\begin{array}{c}-.1263^{*} \\
(-4.02)\end{array}$ \\
\hline Transit Pass. Miles Travel Per Capita (PMTPC) & $\begin{array}{c}-.0274^{*} \\
(-5.52)\end{array}$ & $\begin{array}{c}-.02667^{*} \\
(-5.51)\end{array}$ & $\begin{array}{c}-.0461 * \\
(-8.73)\end{array}$ & $\begin{array}{c}-.0176 * \\
(-3.70)\end{array}$ \\
\hline Percent Construction Employment (CON) & $\begin{array}{l}.2460 * \\
(15.01)\end{array}$ & $\begin{array}{l}.1883^{*} \\
(10.80)\end{array}$ & $\begin{array}{l}.2310^{*} \\
(14.01)\end{array}$ & $\begin{array}{l}.0338^{*} \\
(2.22)\end{array}$ \\
\hline Percent Wholesale Employment (WHOLE) & $\begin{array}{c}.1324^{*} \\
(9.54)\end{array}$ & $\begin{array}{l}.1581^{*} \\
(11.40)\end{array}$ & $\begin{array}{l}.0699 * \\
(4.90)\end{array}$ & $\begin{array}{l}-.0061 \\
(-0.33)\end{array}$ \\
\hline Central Region (CENTRAL) & & $\begin{array}{c}-.0918 * \\
(-8.57)\end{array}$ & & \\
\hline Eastern Region (EASTERN) & & $\begin{array}{l}-.1079 * \\
(-10.89)\end{array}$ & & \\
\hline Very Large Population Size (VLG) & & & $\begin{array}{c}.0874 * \\
(6.73)\end{array}$ & \\
\hline Large Population Size (LRG) & & & $\begin{array}{c}.0588 * \\
(6.71)\end{array}$ & \\
\hline Small Population Size (SML) & & & $\begin{array}{c}-.0806^{*} \\
(-8.37)\end{array}$ & \\
\hline Constant & $\begin{array}{l}-2.216 \\
(-9.83)\end{array}$ & $\begin{array}{l}-1.561 \\
(-6.48)\end{array}$ & $\begin{array}{l}-1.254 \\
(-5.38)\end{array}$ & $\begin{array}{l}-.0340 \\
(-0.09)\end{array}$ \\
\hline Number of Urban Areas & 87 & 87 & 87 & 87 \\
\hline Number of Years & 28 & 28 & 28 & 28 \\
\hline Number of Total Obs. & $2361 * *$ & $2361 * *$ & $2361 * *$ & $2361 * *$ \\
\hline R-squared & 0.6372 & 0.6552 & 0.6630 & 0.9386 \\
\hline
\end{tabular}

* Represents statistical significance at the 5\% level.

**Represents smaller R-squared due to missing obs. from BEA employment statistics.

Column (C) uses population size groupings for very large, large, medium and small urban areas as fixed effects, so that medium is omitted as the control group (see Appendix A for categorical definitions and a list of urban areas in each group). The coefficients exhibit a linear upward trend; VMTPC is found to be higher the larger the population size bracket an urban area falls into, ceteris paribus.

Column (A) is included to show a regression with no group-specific fixed effects. It is apparent that the R-squared is much smaller and the coefficients are quite different in Column (A) when compared to Column (D) (which uses the standard urban area fixed effects). Column (D), similarly to all other regressions that feature urban area and yearly fixed effects, does not report fixed effects coefficients for each individual urban area and year for the sake of brevity (see Appendix D for urban area and yearly fixed effects' coefficients from the most refined model). 
Table 5.3 shows that the use of urban area-specific fixed effects and yearly fixed effects provides the best fit for the model, as indicated by the R-squared of approximately 0.94 .

\subsubsection{Distributed Lag Results}

Table 5.4 presents a distributed lag regression output and provides the calculated long-run elasticities for the independent variables. The long-run elasticities found in Column (B) are closely comparable to the coefficients from the standard fixed effects model (Column (D) from Tables 5.2 and 5.3), which are labeled in Table 5.4 as Column (D) for comparison.

Alternatively, the short-run elasticites, which are found in the distributed lag regression's coefficients, and shown in Column (A) are considerably smaller.

Table 5.4: Distributed Lag Model "Dependent Variable: VMTPC" (1982-2009)

\begin{tabular}{|c|c|c|c|}
\hline Variable Name & $\begin{array}{c}\text { (A) } \\
\text { Distributed Lag } \\
\text { Model }\end{array}$ & $\begin{array}{c}\text { (B) } \\
\text { Long-Run } \\
\text { Elasticity from (A) }\end{array}$ & $\begin{array}{c}\text { !(D) } \\
\text { Standard OLS } \\
\text { from Table } 5.2 \\
\end{array}$ \\
\hline Lagged VMTPC One Year (L1_VMTPC) & $\begin{array}{c}.7961 * \\
(66.65) \\
\end{array}$ & & \\
\hline Lane Miles Per Capita (LMPC) & $\begin{array}{l}.1050^{*} \\
(8.71)\end{array}$ & .5150 & $\begin{array}{l}.4994 * \\
(28.10) \\
\end{array}$ \\
\hline Personal Income Per Capita (PIPC) & $\begin{array}{l}.0498 * \\
(2.44) \\
\end{array}$ & .2442 & $\begin{array}{l}.2487 * \\
(7.38) \\
\end{array}$ \\
\hline Population Density (DENSITY) & $\begin{array}{c}-.0210 * \\
(-2.24)\end{array}$ & .1030 & $\begin{array}{l}-.0152 \\
(-0.96) \\
\end{array}$ \\
\hline Real Fuel Cost (RFC) & $\begin{array}{l}-.0263 \\
(-1.47) \\
\end{array}$ & -.1290 & $\begin{array}{c}-.1263 * \\
(-4.02)\end{array}$ \\
\hline Transit Pass. Miles Travel Per Capita (PMTPC) & $\begin{array}{l}-.0038 \\
(-1.33) \\
\end{array}$ & -.0186 & $\begin{array}{c}-.0176^{*} \\
(-3.70) \\
\end{array}$ \\
\hline Percent Construction Employment (CON) & $\begin{array}{l}.0104 \\
(1.15) \\
\end{array}$ & .0510 & $\begin{array}{l}.0338 * \\
(2.22)\end{array}$ \\
\hline Percent Wholesale Employment (WHOLE) & $\begin{array}{l}.0024 \\
(0.22)\end{array}$ & .0118 & $\begin{array}{l}-.0061 \\
(-0.33)\end{array}$ \\
\hline Constant & $\begin{array}{l}.1888 \\
(0.80) \\
\end{array}$ & & $\begin{array}{l}-.0340 \\
(-0.09) \\
\end{array}$ \\
\hline Number of UAs & 87 & & 87 \\
\hline Number of Years & 28 & & 28 \\
\hline Number of Total Obs. & $2344 * *$ & & $2361 * *$ \\
\hline R-squared & 0.9673 & & 0.5529 \\
\hline
\end{tabular}

* Represents statistical significance at the $5 \%$ level.

**Represents smaller R-squared due to missing observations from BEA employment statistics.

! Represents the optimal specification; to which other models can be compared.

Recall the long-term elasticities are calculated as $\varepsilon=\frac{\lambda}{1-\gamma}$, where $\lambda$ are the short-run elasticities (found in the regression's coefficients), and $\gamma$ is the coefficient of the one year lag of VMTPC. We find a very inelastic price elasticity in the short-run of -.0263 (the $R F C$ coefficient in Table 5.4 ), while the long-run price elasticity is $\frac{-.0263}{1-.7961}=-.1290$, which is very close to the value of -.1263 (found in the standard fixed effects model in Column (D)). 
Thus, the long-run price elasticity found here is approximately five times larger than the shortrun elasticity of demand for VMTPC, as compared to Noland and Coward (2000) who found the long-term price elasticity to be about 3.5 times as large as the short-run elasticity. Note that the larger R-squared in the distributed lag model is simply an artifact of the strong relation between VMTPC and its lag and does not necessarily reflect a superior design.

\subsubsection{Two-Stage Least Squares Results}

This section depicts the instrumental variable two-stage least squares model that corrects for the endogeneity of $L M P C$. The varying Columns (A) through (D) are to the exact same specification as the columns presented in the original fixed effects model in Table 5.2.

Table 5.5 shows the first stage of the 2SLS model, with $L M P C$ as the dependent variable being explained by the instrument, $U L A$, and all the other exogenous variables in the equation. In all four columns, $U L A$ takes on a negatively significant coefficient. Additionally, in the first stage, one can see that DENSITY is strongly negatively correlated to $L M P C$. This relation explains why the DENSITY coefficient in the standard fixed effects model is biased away from its true negative value, shown in the second stage of the 2SLS.

\begin{tabular}{|c|c|c|c|c|}
\hline Variable Name & $\begin{array}{c}\text { (A) } \\
2 \text { SLS }\end{array}$ & $\begin{array}{c}\text { (B) } \\
\text { 2SLS }\end{array}$ & $\begin{array}{c}(\mathrm{C}) \\
\text { 2SLS }\end{array}$ & $\begin{array}{c}\text { !(D) } \\
2 \text { SLS }\end{array}$ \\
\hline Urban Land Area (ULA) & $\begin{array}{l}-.3948^{*} \\
(-21.67)\end{array}$ & $\begin{array}{l}-.4112^{*} \\
(-22.27)\end{array}$ & $\begin{array}{l}-.4226^{*} \\
(-23.07)\end{array}$ & $\begin{array}{c}-.4128^{*} \\
(-22.25)\end{array}$ \\
\hline Personal Income Per Capita (PIPC) & $\begin{array}{l}.0705^{*} \\
(2.05)\end{array}$ & $\begin{array}{l}.0041 \\
(0.11)\end{array}$ & $\begin{array}{l}-.0282 \\
(-0.76)\end{array}$ & $\begin{array}{l}.0407 \\
(1.12)\end{array}$ \\
\hline Population Density (DENSITY) & $\begin{array}{l}-.4108^{*} \\
(-19.27)\end{array}$ & $\begin{array}{l}-.4023 * \\
(-18.48)\end{array}$ & $\begin{array}{l}-.4448^{*} \\
(-20.97)\end{array}$ & $\begin{array}{l}-.4176^{*} \\
(-19.20)\end{array}$ \\
\hline Real Fuel Cost (RFC) & $\begin{array}{c}-.1428^{*} \\
(-4.34)\end{array}$ & $\begin{array}{c}-.1260^{*} \\
(-3.75)\end{array}$ & $\begin{array}{c}-.1505^{*} \\
(-4.50)\end{array}$ & $\begin{array}{c}-.1199^{*} \\
(-3.55)\end{array}$ \\
\hline Transit Pass. Miles Travel Per Capita (PMTPC) & $\begin{array}{l}-.0009 \\
(-0.17)\end{array}$ & $\begin{array}{l}.0016 \\
(0.31)\end{array}$ & $\begin{array}{l}.0020 \\
(0.40)\end{array}$ & $\begin{array}{l}.0027 \\
(0.53)\end{array}$ \\
\hline Public Private Employment Ratio (PUB) & $\begin{array}{l}.1904^{*} \\
(9.59)\end{array}$ & & & \\
\hline Percent Finance-Insure-Real Estate Employment(FIN) & & $\begin{array}{c}-.0299 * \\
(-2.57)\end{array}$ & & \\
\hline Percent Construction Employment (CON) & & $\begin{array}{l}-.0080 \\
(-0.48)\end{array}$ & $\begin{array}{l}-.0161 \\
(-0.98)\end{array}$ & $\begin{array}{l}-.0223 \\
(-1.36)\end{array}$ \\
\hline Percent Manufacturing Employment (MANU) & & $\begin{array}{c}-.0623 * \\
(-4.22)\end{array}$ & $\begin{array}{c}-.0552 * \\
(-3.82)\end{array}$ & \\
\hline Percent Wholesale Employment (WHOLE) & & $\begin{array}{c}-.1002 * \\
(-5.10)\end{array}$ & & $\begin{array}{c}-.0937 * \\
(-4.76)\end{array}$ \\
\hline Percent Retail Employment (RETAIL) & & $\begin{array}{c}-.1016^{*} \\
(-2.53)\end{array}$ & & \\
\hline Constant & $\begin{array}{c}6.048 \\
(13.79) \\
\end{array}$ & $\begin{array}{c}5.704 \\
(11.86) \\
\end{array}$ & $\begin{array}{c}7.000 \\
(14.94) \\
\end{array}$ & $\begin{array}{c}5.809 \\
(12.18) \\
\end{array}$ \\
\hline R-squared & 0.1506 & 0.1315 & 0.1504 & 0.1484 \\
\hline
\end{tabular}


The second stage regressions are presented in Table 5.6. It is noticeable that now all variables in the optimal model specification in Column (D) are significant at the five percent level and have the expected sign. The model reported in column (D) is considered to be the preferred model for three reasons. First, there is no longer a bias due to simultaneity, second because all coefficients are significant and consistent with expectations of economic theory. Finally this variable specification has the largest R-squared of any of the four 2SLS models, indicating the best econometric fit. The 2SLS correction significantly decreased the $L M P C$ elasticity from .4994 in the standard OLS model down to .2524 in the 2SLS. This smaller result is more comparable to the $L M P C$ elasticites found in the literature (Noland, 2001; Fulton et al., 2000).

TABLE 5.6 2SLS Model with Varying Employment Mix Variables Second Stage "Dependent Variable: VMTPC," Instrument: ULA" (1982-2009)

\begin{tabular}{|c|c|c|c|c|}
\hline Variable Name & $\begin{array}{c}\text { (A) } \\
\text { 2SLS with } \\
\text { UA \& Year } \\
\text { Effects }\end{array}$ & $\begin{array}{c}\text { (B) } \\
\text { 2SLS with } \\
\text { UA \& Year } \\
\text { Effects }\end{array}$ & $\begin{array}{c}(\mathrm{C}) \\
\text { 2SLS with } \\
\text { UA \& Year } \\
\text { Effects }\end{array}$ & $\begin{array}{c}\text { !(D) } \\
\text { 2SLS with } \\
\text { UA \& Year } \\
\text { Effects }\end{array}$ \\
\hline Predicted Lane Miles Per Capita $\left(\overline{L M P C}_{i t}\right)$ & $\begin{array}{c}.2753 * \\
(6.14) \\
\end{array}$ & $\begin{array}{c}.2684^{*} \\
(6.36) \\
\end{array}$ & $\begin{array}{c}.3315^{*} \\
(8.31) \\
\end{array}$ & $\begin{array}{c}.2524^{*} \\
(5.80) \\
\end{array}$ \\
\hline Personal Income Per Capita (PIPC) & $\begin{array}{l}.3425^{*} \\
(10.14) \\
\end{array}$ & $\begin{array}{l}.1424^{*} \\
(4.02)\end{array}$ & $\begin{array}{c}.1630^{*} \\
(4.79) \\
\end{array}$ & $\begin{array}{l}.2630^{*} \\
(7.47) \\
\end{array}$ \\
\hline Population Density (DENSITY) & $\begin{array}{c}-.0343^{*} \\
(-2.03) \\
\end{array}$ & $\begin{array}{l}-.0026 \\
(-0.16) \\
\end{array}$ & $\begin{array}{l}-.0077 \\
(-0.47) \\
\end{array}$ & $\begin{array}{c}-.0431 * \\
(-2.52)\end{array}$ \\
\hline Real Fuel Cost (RFC) & $\begin{array}{c}-.1534^{*} \\
(-4.71) \\
\end{array}$ & $\begin{array}{c}-1687^{*} \\
(-5.26) \\
\end{array}$ & $\begin{array}{c}-.1591 * \\
(-5.07)\end{array}$ & $\begin{array}{c}-.1542^{*} \\
(-4.67)\end{array}$ \\
\hline Transit Pass. Miles Travel Per Capita (PMTPC) & $\begin{array}{c}-.0247^{*} \\
(-4.96)\end{array}$ & $\begin{array}{l}-.0237^{*} \\
(-4.83)\end{array}$ & $\begin{array}{c}-.0231 * \\
(-4.87) \\
\end{array}$ & $\begin{array}{c}-.0228 * \\
(-4.53)\end{array}$ \\
\hline Public Private Employment Ratio (PUB) & $\begin{array}{c}.1207 * \\
(5.44)\end{array}$ & & & \\
\hline Percent Finance-Insure-Real Estate Employment(FIN) & & $\begin{array}{l}-.0004 \\
(-0.04)\end{array}$ & & \\
\hline Percent Construction Employment (CON) & & $\begin{array}{c}.0716^{*} \\
(4.55) \\
\end{array}$ & $\begin{array}{c}.0595^{*} \\
(3.93) \\
\end{array}$ & $\begin{array}{c}.0332 * \\
(2.09) \\
\end{array}$ \\
\hline Percent Manufacturing Employment (MANU) & & $\begin{array}{l}-1742^{*} \\
(-12.44) \\
\end{array}$ & $\begin{array}{l}-1724^{*} \\
(-12.88) \\
\end{array}$ & \\
\hline Percent Wholesale Employment (WHOLE) & & $\begin{array}{c}-.0436^{*} \\
(-2.24)\end{array}$ & & $\begin{array}{c}-.0411 * \\
(-2.06)\end{array}$ \\
\hline Percent Retail Employment (RETAIL) & & $\begin{array}{c}-.0774^{*} \\
(-2.04)\end{array}$ & & \\
\hline Constant & $\begin{array}{c}-.4738 * \\
(-1.30) \\
\end{array}$ & $\begin{array}{l}.7233 \\
(1.80) \\
\end{array}$ & $\begin{array}{l}.7300 \\
(1.87) \\
\end{array}$ & $\begin{array}{l}.1920 \\
(0.47) \\
\end{array}$ \\
\hline Number of Urban Areas & 87 & 87 & 87 & 87 \\
\hline Number of Years & 28 & 28 & 28 & 28 \\
\hline Number of Total Obs. & 2436 & $2344 * *$ & $2422 * *$ & $2361 * *$ \\
\hline R-squared & 0.5348 & 0.3251 & 0.3736 & 0.5339 \\
\hline
\end{tabular}

* Represents statistical significance at the $5 \%$ level.

**Represents smaller R-squared due to missing observations from BEA employment statistics.

! Represents the optimal specification; to which other models can be compared. 
Column (D) in Table 5.6 is the final model used to calculate elasticities for this study. In consequence, a 10 percent increase in personal income per capita $(P I P C)$ correlates with close to a 2.6 percent increase in VMTPC due to the coefficient of .2524. LMPC behaves similarly, with a 10 percent increase in lane miles per capita resulting in just over a 2.6 percent increase in VMTPC. RFC, DENSITY, and PMTPC all show significantly negative elasticities of -.1542, .0431 , and -.0228 , respectively.

Finally, CON has an elasticity of .0332 , meaning that a 10 percent increase in the percentage of an urban area's workforce that is employed in the construction industry corresponds to a 0.3 percent increase in $V M T P C$. The same change in $M A N U$ corresponds to a decrease in $V M T P C$ of about 0.4 percent, possibly due to manufacturing's comparatively less vehicle-intense production, distribution and sales processes.

\subsubsection{Predicted Values Applied to Individual Urban Area Granger Causality}

This section takes the 87 urban areas from the two-stage least squares derived demand analysis presented in Column (D) of Table 5.6 and separates them in order to study each area as an individual time-series. From this model predicted values of the dependent variable, the natural logarithm of VMT per capita $(\overline{V M T P C})$, are taken. These predicted values take into account the characteristics that differ across urban areas. The predicted values are then inserted into the Granger causality model using the natural logarithm of per capita personal income (PIPC). Table 5.7 shows Granger causation between $\overline{V M T P C}$ and PIPC in individual urban areas from 1982-2009 using the predicted values that control for differences in urban area characteristics.

Results are reported in Table 5.7. Note that while results in Table 4.10 for areas such as Portland-Vancouver-Hillsboro showed bidirectional causation, after controlling for significant urban area characteristics determining $V M T P C$, no causation is found in either direction. This further illustrates the need to carefully design $V M T P C$ reduction policies that take into account important urban area specific characteristics.

\begin{tabular}{lcc}
$\begin{array}{l}\text { Table 5.7 Granger Causality Using Predicted Values: Individual Urban Areas } \\
\text { (1982-2009) }\end{array}$ & \multicolumn{2}{c}{ Probability $>$ Chi2 } \\
\cline { 2 - 3 } Regression Name & $\begin{array}{c}(\overline{V M T P C}) \\
\text { causes PIPC }\end{array}$ & $\begin{array}{c}\text { PIPC causes } \\
(\overline{V M T P C})\end{array}$ \\
\hline Akron, OH & 0.542 & 0.066 \\
Albany-Schenectady-Troy, NY & 0.644 & $0.013^{*}$ \\
Albuquerque, NM & 0.668 & 0.729 \\
Allentown-Bethlehem-Easton, PA-NJ & 0.597 & 0.697 \\
Anchorage, AK & $0.000^{*}$ & 0.297 \\
Atlanta-Sandy Springs-Marietta, GA & 0.179 & 0.840 \\
Austin-Round Rock-San Marcos, TX & 0.729 & 0.182 \\
Bakersfield-Delano, CA & 0.224 & 0.522 \\
Baltimore-Towson, MD & 0.324 & 0.075 \\
Beaumont-Port Arthur, TX & 0.068 & 0.087 \\
Birmingham-Hoover, AL & $0.011^{*}$ & 0.275
\end{tabular}




\begin{tabular}{|c|c|c|}
\hline Boston-Cambridge-Quincy, MA-NH & 0.320 & 0.807 \\
\hline Boulder, CO & $0.011 *$ & 0.148 \\
\hline Bridgeport-Stamford-Norwalk, CT & 0.482 & 0.308 \\
\hline Brownsville-Harlingen, TX & $0.026^{*}$ & 0.219 \\
\hline Buffalo-Niagara Falls, NY & 0.967 & $0.026^{*}$ \\
\hline Cape Coral-Fort Myers, FL & 0.079 & 0.234 \\
\hline Charleston-North Charleston-Summerville, SC & $0.000 *$ & 0.121 \\
\hline Charlotte-Gastonia-Rock Hill, NC-SC & 0.077 & 0.121 \\
\hline Chicago-Joliet-Naperville, IL-IN-WI & $0.040^{*}$ & 0.132 \\
\hline Cincinnati-Middletown, OH-KY-IN & 0.728 & 0.184 \\
\hline Cleveland-Elyria-Mentor, $\mathrm{OH}$ & 0.451 & 0.165 \\
\hline Colorado Springs, CO & 0.443 & 0.292 \\
\hline Columbia, SC & 0.269 & 0.105 \\
\hline Columbus, $\mathrm{OH}$ & 0.434 & 0.101 \\
\hline Corpus Christi, TX & 0.172 & 0.739 \\
\hline Dallas-Fort Worth-Arlington, TX & 0.286 & 0.339 \\
\hline Dayton, $\mathrm{OH}$ & 0.332 & 0.341 \\
\hline Denver-Aurora-Broomfield, CO & $0.006^{*}$ & 0.467 \\
\hline Detroit-Warren-Livonia, MI & 0.089 & 0.299 \\
\hline El Paso, TX & 0.167 & 0.459 \\
\hline Eugene-Springfield, OR & 0.537 & 0.164 \\
\hline Fresno, CA & $0.022 *$ & 0.130 \\
\hline Grand Rapids-Wyoming, MI & 0.320 & 0.834 \\
\hline Hartford-West Hartford-East Hartford, CT & 0.393 & $0.028 *$ \\
\hline Honolulu, HI & 0.926 & 0.473 \\
\hline Houston-Sugar Land-Baytown, TX & 0.505 & 0.451 \\
\hline Indianapolis-Carmel, IN & 0.079 & 0.164 \\
\hline Jacksonville, FL & $0.010^{*}$ & 0.331 \\
\hline Kansas City, MO-KS & 0.320 & 0.108 \\
\hline Knoxville, TN & 0.417 & 0.475 \\
\hline Laredo, TX & 0.598 & 0.490 \\
\hline Las Vegas-Paradise, NV & 0.318 & 0.712 \\
\hline Little Rock-North Little Rock-Conway, AR & 0.922 & $0.015^{*}$ \\
\hline Los Angeles-Long Beach-Santa Ana, CA & 0.787 & 0.942 \\
\hline Louisville-Jefferson County, KY-IN & 0.713 & 0.457 \\
\hline Memphis, TN-MS-AR & 0.187 & $0.039 *$ \\
\hline Miami-Fort Lauderdale-Pompano Beach, FL & $0.002 *$ & $0.001 *$ \\
\hline Milwaukee-Waukesha-West Allis, WI & 0.203 & $0.044^{*}$ \\
\hline Minneapolis-St. Paul-Bloomington, MN-WI & 0.256 & 0.225 \\
\hline Nashville-Davidson-Murfreesboro-Franklin, TN & $0.035^{*}$ & 0.633 \\
\hline New Haven-Milford, CT & 0.473 & 0.222 \\
\hline New Orleans-Metairie-Kenner, LA & 0.641 & 0.450 \\
\hline New York-Northern New Jersey-Long Island, NY-NJ & 0.321 & 0.251 \\
\hline Oklahoma City, OK & 0.144 & 0.212 \\
\hline Omaha-Council Bluffs, NE-IA & 0.564 & $0.003 *$ \\
\hline Orlando-Kissimmee-Sanford, FL & 0.481 & 0.317 \\
\hline
\end{tabular}




\begin{tabular}{|c|c|c|}
\hline Oxnard-Thousand Oaks-Ventura, CA & 0.633 & $0.005^{*}$ \\
\hline Pensacola-Ferry Pass-Brent, FL & 0.282 & $0.028 *$ \\
\hline Philadelphia-Camden-Wilmington, PA-NJ-DE-MD & 0.237 & 0.665 \\
\hline Phoenix-Mesa-Glendale, AZ & 0.818 & 0.470 \\
\hline Pittsburgh, PA & 0.866 & 0.389 \\
\hline Portland-Vancouver-Hillsboro, OR-WA & 0.084 & 0.312 \\
\hline Poughkeepsie-Newburgh-Middletown, NY & $0.047 *$ & $0.049 *$ \\
\hline Providence-New Bedford-Fall River, RI-MA & 0.924 & 0.051 \\
\hline Raleigh-Cary, NC & 0.315 & $0.001 *$ \\
\hline Richmond, VA & 0.181 & $0.001 *$ \\
\hline Riverside-San Bernardino-Ontario, CA & 0.797 & 0.626 \\
\hline Rochester, NY & 0.733 & $0.006^{*}$ \\
\hline Sacramento-Arden-Arcade-Roseville, CA & 0.581 & 0.602 \\
\hline Salem, OR & 0.447 & $0.037^{*}$ \\
\hline Salt Lake City, UT & 0.123 & 0.623 \\
\hline San Antonio-New Braunfels, TX & 0.314 & 0.231 \\
\hline San Diego-Carlsbad-San Marcos, CA & 0.126 & 0.100 \\
\hline San Francisco-Oakland-Fremont, CA & 0.660 & 0.428 \\
\hline San Jose-Sunnyvale-Santa Clara, CA & $0.010 *$ & 0.226 \\
\hline Seattle-Tacoma-Bellevue, WA & 0.615 & 0.301 \\
\hline Spokane, WA & 0.453 & 0.535 \\
\hline Springfield, MA & 0.803 & 0.796 \\
\hline St. Louis, MO-IL & 0.956 & $0.046^{*}$ \\
\hline Tampa-St. Petersburg-Clearwater, FL & $0.008^{*}$ & 0.064 \\
\hline Toledo, $\mathrm{OH}$ & 0.141 & 0.179 \\
\hline Tucson, AZ & 0.919 & 0.330 \\
\hline Tulsa, OK & 0.639 & 0.113 \\
\hline Virginia Beach-Norfolk-Newport News, VA-NC & 0.110 & 0.648 \\
\hline Washington-Arlington-Alexandria, DC-VA-MD-WV & 0.325 & 0.137 \\
\hline Wichita, KS & 0.762 & 0.603 \\
\hline Urban Areas (Observations per panel) & $87(25)$ & $87(25)$ \\
\hline Count of Significant Urban Areas at the 5\% level & 14 & 16 \\
\hline Percent of Areas that are Significant at the 5\% level & $16.09 \%$ & $18.39 \%$ \\
\hline
\end{tabular}

* Represents statistical significance at $5 \%$ level (H1: Granger causation). 


\subsection{CONCLUSIONS}

The relationship between VMT growth and growth in economic activity is complex. This study uses time-series techniques and Granger causality to provide insight into these casual relationships. Historic national level data shows significant unidirectional Granger causation from economic activity to VMT from 1929-2009; a result consistent with the concept that VMT is a normal good. This differs from Pozdena's (2009) results that found bidirectional causation at the national level. Pozdena's bidirectional results are shown to be valid for the 1949-2007 and 1949-1982 periods, but during the time period of interest for prospective GHG and transportation system efficiency policymaking, 1982-2009, bidirectional causation is not found and significant variation is seen in the results between national and urban area data.

Using national data the causal relationship between VMT and GDP is found to be dependent on the macroeconomy and the stage of the business cycle. VMT tends to lead or cause economic activity in downturns, confirming the use of VMT-related measures as indicators of turning points in the macroeconomic business cycle. However, in macroeconomic upturns unidirectional causation is seen flowing from economic activity to VMT growth. A majority of the findings suggest that policies designed to reduce VMT may be used without the threat of compromising national economic activity, yet results were found to differ for urban and non-urban geographic areas.

For very large, large, and medium-sized urban areas, no significant causal relationship was found between VMT and economic activity. Only for small urban areas and the national sample, which includes rural areas, was some reverse causation found. This result is consistent with the hypothesis that smaller urban areas are still in the stage of growth where there is substantial feedback from increases in VMT and personal income. It is also possible that smaller urban areas lack the transit alternatives to help mitigate negative impacts from exogenous reductions in VMT.

The derived demand analysis is applied to explore the relationship between VMT and economic activity on a more micro level to determine where potential adverse impacts might arise and how policy could be formulated to mitigate those impacts. Multiple factors were found to significantly contribute to the demand for VMT in urban areas, including lane miles, personal income, population density, fuel cost, transit use, and the percent of employment in the construction or wholesale sectors. Both transit use and population density are negatively related to VMTPC, reinforcing why smaller, less dense areas with less transit may not be able to provide substitutes for VMT, leading to a causal relationship with economic activity.

With all these factors held constant, per capita VMT is found to be higher the more western and the larger the population size of an urban area. However, VMT-reduction policies should methodically examine each of these factors on an area-by-area basis. This study does not imply that VMT reductions can universally be introduced into a transportation system without reducing mobility or economic activity, but suggests that in under normal circumstances in well- 
developed urban areas, it is reasonable that GHG-related VMT-reduction policies would not result in significant drops in economic activity. 


\subsection{REFERENCES}

$74^{\text {th }}$ Oregon Legislative Assembly. "H.B. 3543 2."

http://www.leg.state.or.us/07reg/measpdf/hb3500.dir/hb3543.en.pdf., Salem, OR, 2007.

Blanchard, Olivier. "Sustaining a Global Recovery." Finance \& Development, Volume 46, number 3, 2009.

Bunge, Mario. "Causality." Harvard University Press, 1959.

Breusch, T. S., and A. R. Pagan. "The LM Test and Its Applications to Model Specification in Econometrics." Review of Economic Studies Vol. 47, 1980: pp. 239-254.

Commerce_Committee. Federal Surface Transportation Policy and Planning Act of 2009. (http://commerce.senate.gov/public/index.cfm), U.S. Senate Commerce Committee, 2009.

Dickey, D. A., and W. A. Fuller. "Distribution of the Estimators for Auto-regressive Time Series with Unit Roots." Journal of the American Statistical Association, vol. 74, 1979: pp. 427-431.

Dougherty, Christopher. Introduction to Econometrics, Third Edition. New York: Oxford University Press, 2007.

N. D. Eckstein. "The Relationship Between Vehicle Miles Traveled and Economic Activity." Master's Thesis. Oregon State University at Corvallis, Oregon. 2011.

http://hdl.handle.net/1957/22829

Engle, Robert F, and Clive W. J. Granger. "Co-integration and Error Correction." Econometrica, Vol. 55, No. 2., 1987: pp. 251-276.

Fulton, Lewis M, Robert B Noland, Daniel J Meszler, and John V Thomas. "A Statistical

Analysis of Induced Travel Effects." Journal of Transportation and Statistics, vol. 3, no. 1, 2000: pp. 1-14.

Frank, L.D., and G. Pivo. "Impacts of Mixed Use and Density on Utilization of Three Modes of Travel: Single-Occupant Vehicle, Transit, and Walking." Transportation Research Record, Vol 1466, 1995: pp. $44-52$.

Goodwin, Phil, Joyce Dargay, and Mark Hanly. "Elasticities of Road Traffic and Fuel Consumption with Respect to Price and Income: A Review." Transport Reviews, Vol. 24, No. 3, 2004: pp. 275-292. 
Goodwin, Phil. "Empirical Evidence on Induced Traffic, a Review and Synthesis." Transportation, Vol. 23, 1996: pp. 35-54.

Graham, D. J., and S. Glaister. "Road Traffic Demand Elasticity Estimates: A Review." Transport Reviews, 24(3), 2004: pp. 261-274.

Granger, Clive W. J. "Investigating Causal Relations by Econometric Models and Crossspectoral Methods." Econometrica, Volume 37, Issue 3, 1969: pp. 424-438.

Greene, David L., and Stephen E. Plotkin. "Reducing GreenHouse Gas Emmisions from U.S. Transportation." Pew Center on Global Climate Change, 2011: pp. 1-95.

Greene, William H. Econometric Analysis Sixth Edition. Upper Saddle River, NJ: Pearson Prentice Hall, 2008.

Gregor, B. Background Report: The Status of Oregon Greenhouse Gas Emissions and Analysis. In Metropolitan Planning OrganizationGreenhouse Gas Emissions Task Force, Salem, OR, 2009.

Hamilton, James D. Time Series Analysis. Princeton, NJ: Princeton University Press, 1994.

Hansen, M., and Y. Huang. "Road Supply and Traffic in California Urban Areas." Transportation Research A 31, pp. 205-218.

Holtzclaw, J. Explaining Urban Density And Transit Impacts On Auto Use . (California Energy Commission Docket No. 89), pp. 23., San Francisco: Natural Resources Defense Council, 1991.

Ivanov, V., and L. Kilian. "A Practitioner's Guide to Lag Order Selection for VAR Impulse Response Analysis.” Nonlinear Dynamics \& Econometrics: Vol. 9: No. 1, 2005: Article 2.

Litman, Todd. "Are VMT Targets Justified?" Victoria Transportation Policy Institute, 2010.

Lütkepohl, H. New Introduction to Multiple Time Series Analysis. Berlin, Heidelberg, Germany: Springer-Verlag, 2005.

McMullen, B. S., L. Zhang, K. Nakahara, and D. Valluri . "The Short- and Long-Run Impact of a Vehicle Mileage Fee on Income and Spatial Equity." Journal of the Transportation Research Board, No. 2115, 2009: pp. 110-118.

Noland, Robert B. "Relationships between Highway Capacity and Induced Vehicle Travel." Transportation Research Part A: Policy and Practice, Volume 35, Issue 1, 2001: pp. 47-72.

Noland, Robert B., and William A Cowart. "Analysis of Metropolitan Highway Capacity and the growth." Transportation Volume 27, Number 4, 2000: pp. 363-390.

Office of Budget and Management. 2010 Standards for Delineating Metropolitan and Micropolitan Statistical Areas. June 28th, 2010. 
http://www.whitehouse.gov/sites/default/files/omb/assets/fedreg_2010/06282010_metro_standar ds-Complete.pdf.

Pells, S.R. "User Response to New Road Capacity: A Review of Published Evidence ." Institute for Transport Studies, Leeds University, 1989: Working Paper 283.

Polzin, S.E., X. Chu, and L. Toole-Holt. "Forecasts of future vehicle miles of travel in the United States." Transportation Research Record, 2004.

Pozdena, Randall. "Driving The Economy." Cascade Policy Institute, 2009.

Puentes, Robert, and Adie Tomer. "The Road ...Less Travelled: An Analysis of Vehicle Miles Traveled Trends in the U.S." Washington: Brookings Institution (Washington: Brookings Institution), 2008.

Pushkarev, B., and J. Zupan. Urban Rail in America: An Exploration of Criteria for FixedGuideway Transit. U. S. Department of Transportation, Report No. UMTA-NY-06-0061-80-1, pp. 31., Washington D.C.: Urban Mass Transportation Administration, 1980.

Stock, James H., and Watson, Mark W. "Vector Autoregressions." Journal of Economic Perspectives, Vol. 15 No. 4, 2001: pp. 101-115.

Texas Transportation Institute. 2010 Annual Urban Mobility Report. 2011. http://mobility.tamu.edu/ums/.

The National Bureau of Economic Research. U.S. Business Cycle Expansions and Contractions. July 7th, 2011. http://www.nber.org/cycles.html.

U.S. Census Bureau. 2010 Census Urban and Rural Classification and Urban Area Criteria. August 17th, 2010. http://www.census.gov/geo/www/ua/2010urbanruralclass.html.

U.S. Department of Commerce. Bureau of Economic Analysis: Local Area Personal Income. April 21st, 2011. http://www.bea.gov/regional/reis/.

U.S. Department of Transportation. Federal Highway Administration: Highway Statistics 2009. April 20th , 2011. http://www.fhwa.dot.gov/policyinformation/statistics/2009/vmt421.cfm.

Winkelman, Steve, Allison Bishins, and Chuck Kooshian. "Cost effective GHG reductions through smart growth \& improved transportation choices." Center for Clean Air Policy, 2009. 


\subsection{APPENDICES}





\section{APPENDIX A \\ URBAN AREA POPULATION SIZE AND REGIONAL GROUPINGS}

\begin{tabular}{|c|c|c|}
\hline Group & $\begin{array}{c}\text { Population } \\
\text { Grouping }\end{array}$ & List of UAs (alphabetical) \\
\hline $\begin{array}{l}\text { Very } \\
\text { Large } \\
\text { (vlg) }\end{array}$ & $\begin{array}{l}\text { More than } \\
3 \text { million }\end{array}$ & $\begin{array}{l}\text { Atlanta GA, Boston MA-NH-RI, Chicago IL-IN, Dallas-Fort Worth-Arlington TX, } \\
\text { Detroit MI, Houston TX, Los Angeles-Long Beach-Santa Ana CA, Miami FL, New } \\
\text { York-Newark NY-NJ-CT, Philadelphia PA-NJ-DE-MD, Phoenix AZ, San Diego CA, } \\
\text { San Francisco-Oakland CA, Seattle WA, Washington DC-VA-MD }\end{array}$ \\
\hline $\begin{array}{l}\text { Large } \\
\text { (lrg) }\end{array}$ & $\begin{array}{l}\text { Between } 1 \\
\text { and } 3 \\
\text { million }\end{array}$ & $\begin{array}{l}\text { Austin TX, Baltimore MD, Buffalo NY, Charlotte NC-SC, Cincinnati OH-KY-IN, } \\
\text { Cleveland OH, Columbus OH, Denver-Aurora CO, Indianapolis IN, Jacksonville FL, } \\
\text { Kansas City MO-KS, Las Vegas NV, Louisville KY-IN, Memphis TN-MS, } \\
\text { Milwaukee WI, Minneapolis-St. Paul MN, Nashville-Davidson TN, New Orleans } \\
\text { LA, Orlando FL, Pittsburgh PA, Portland OR-WA, Providence RI-MA, Raleigh- } \\
\text { Durham NC, Riverside-San Bernardino CA, Sacramento CA, San Antonio TX, San } \\
\text { Jose CA, St. Louis MO-IL, Tampa-St. Petersburg FL, Virginia Beach VA }\end{array}$ \\
\hline $\begin{array}{l}\text { Medium } \\
\text { (med) }\end{array}$ & $\begin{array}{l}\text { Between } \\
1 / 2 \text { and } 1 \\
\text { million }\end{array}$ & $\begin{array}{l}\text { Akron OH, Albany-Schenectady NY, Albuquerque NM, Allentown-Bethlehem PA- } \\
\text { NJ, Bakersfield CA, Baton Rouge LA, Birmingham AL, Bridgeport-Stamford CT- } \\
\text { NY, Charleston-North Charleston SC, Colorado Springs CO, Dayton OH, El Paso } \\
\text { TX-NM, Fresno CA, Grand Rapids MI, Hartford CT, Honolulu HI, McAllen TX, } \\
\text { New Haven CT, Oklahoma City OK, Omaha NE-IA, Oxnard-Ventura CA, } \\
\text { Poughkeepsie-Newburgh NY, Richmond VA, Rochester NY, Salt Lake City UT, } \\
\text { Sarasota-Bradenton FL, Springfield MA-CT, Toledo OH-MI, Tucson AZ, Tulsa OK, } \\
\text { Wichita KS }\end{array}$ \\
\hline $\begin{array}{l}\text { Small } \\
(\mathrm{sml})\end{array}$ & $\begin{array}{l}\text { Less than } \\
1 / 2 \text { million }\end{array}$ & $\begin{array}{l}\text { Anchorage AK, Beaumont TX, Boise ID, Boulder CO, Brownsville TX, Cape Coral } \\
\text { FL, Columbia SC, Corpus Christi TX, Eugene OR Greensboro NC, Jackson MS, } \\
\text { Knoxville TN, Laredo TX, Little Rock AR, Madison WI, Pensacola FL-AL, Provo } \\
\text { UT, Salem OR, Spokane WA, Stockton CA, Winston-Salem NC, Worcester MA }\end{array}$ \\
\hline
\end{tabular}

Each population size grouping includes 15, 30, 31, and 22 urban areas respectively from largest to smallest. 
Table A.2: Urban Areas Regional Groupings (98 Urban Areas)

\begin{tabular}{|c|c|}
\hline Group & List of UAs (alphabetical) \\
\hline Western & $\begin{array}{l}\text { Albuquerque NM, Anchorage AK, Bakersfield-Delano CA, Boulder CO, Colorado Springs CO, } \\
\text { Denver-Aurora-Broomfield CO, Eugene-Springfield OR, Fresno CA, Honolulu HI, Las Vegas- } \\
\text { Paradise NV, Los Angeles-Long Beach-Santa Ana CA, Oxnard-Thousand Oaks-Ventura CA, } \\
\text { Phoenix-Mesa-Glendale AZ, Portland-Vancouver-Hillsboro OR-WA, Riverside-San Bernardino- } \\
\text { Ontario CA, Sacramento-Arden-Arcade-Roseville CA, Salem OR, Salt Lake City UT, San Diego-- } \\
\text { Carlsbad-San Marcos CA, San Francisco-Oakland-Fremont CA, San Jose-Sunnyvale-Santa Clara } \\
\text { CA, Seattle-Tacoma-Bellevue WA, Spokane WA, Tucson AZ. }\end{array}$ \\
\hline Central & $\begin{array}{l}\text { Atlanta-Sandy Springs-Marietta GA, Austin-Round Rock-San Marcos TX, Beaumont-Port Arthur } \\
\text { TX, Birmingham-Hoover AL, Brownsville-Harlingen TX, Cape Coral-Fort Myers FL, Corpus } \\
\text { Christi TX, Dallas-Fort Worth-Arlington TX, El Paso TX, Houston-Sugar Land-Baytown TX, } \\
\text { Jacksonville FL, Kansas City MO-KS, Laredo TX, Little Rock-North Little Rock-Conway AR, } \\
\text { Miami-Fort Lauderdale-Pompano Beach FL, Minneapolis-St. Paul-Bloomington MN-WI, New } \\
\text { Orleans-Metairie-Kenner LA, Oklahoma City OK, Omaha-Council Bluffs NE-IA, Orlando- } \\
\text { Kissimmee-Sanford FL, Pensacola-Ferry Pass-Brent FL, San Antonio-New Braunfels TX, St. } \\
\text { Louis MO-IL, Tampa-St. Petersburg-Clearwater FL, Tulsa OK, Wichita KS }\end{array}$ \\
\hline Eastern & $\begin{array}{l}\text { Akron OH, Albany-Schenectady-Troy NY, Allentown-Bethlehem-Easton PA-NJ, Baltimore- } \\
\text { Towson MD, Boston-Cambridge-Quincy MA-NH, Bridgeport-Stamford-Norwalk CT, Buffalo- } \\
\text { Niagara Falls NY, Charleston-North Charleston-Summerville SC, Charlotte-Gastonia-Rock Hill } \\
\text { NC-SC, Chicago-Joliet-Naperville IL-IN-WI, Cincinnati-Middletown OH-KY-IN, Cleveland- } \\
\text { Elyria-Mentor OH, Columbia SC, Columbus OH, Dayton OH, Detroit-Warren-Livonia MI, Grand } \\
\text { Rapids-Wyoming MI, Hartford-West Hartford-East Hartford CT, Indianapolis-Carmel IN, } \\
\text { Knoxville TN, Louisville-Jefferson County KY-IN, Memphis TN-MS-AR, Milwaukee- } \\
\text { Waukesha-West Allis WI, Nashville-Davidson-Murfreesboro-Franklin TN, New Haven-Milford } \\
\text { CT, New York-Northern New Jersey-Long Island NY-NJ-PA, Philadelphia-Camden-Wilmington } \\
\text { PA-NJ-DE-MD, Pittsburgh PA, Poughkeepsie-Newburgh-Middletown NY, Providence-New } \\
\text { Bedford-Fall River RI-MA, Raleigh-Cary NC, Richmond VA, Rochester NY, Springfield MA, } \\
\text { Toledo OH, Virginia Beach-Norfolk-Newport News VA-NC, Washington-Arlington-Alexandria } \\
\text { DC-VA-MD-WV }\end{array}$ \\
\hline
\end{tabular}

Each regional grouping includes 24, 26 and 37 urban areas respectively from west to east. 


\section{APPENDIX B}

\section{STABILITY OF THE VAR MODEL}

A post-estimation test is applied to observe the stability of the VAR model. Eigenvalues less than or equal to one are considered to be stable. Table B.1 that of the 14 aggregate VAR regressions described throughout the paper (four national regressions, six urban area regressions); all regressions were found to have "modulus" eigenvalues less than one, and thus satisfy the stability condition for a VAR. The stability of the regressions is also presented graphically in Figure B.1, which shows the unit circle graphs of the same eigenvalues from Table B.1. Eigenvalues are represented by dots on the graphs below, it is quickly apparent that none lie outside the unit circles in any regression and that all regressions are stable (Eckstein, 2011).

Table B.1: Stability of Eigenvalues

\begin{tabular}{|c|c|c|}
\hline Regression Name & Eigenvalue & Modulus \\
\hline \multicolumn{3}{|c|}{ National Data (1929-2009) } \\
\hline VMT-GDP & $\begin{array}{l}.3670302+.5666678 \mathrm{i} \\
.3670302-.5666678 \mathrm{i} \\
.213231+.1729945 \mathrm{i} \\
.213231-.1729945 \mathrm{i}\end{array}$ & $\begin{array}{l}.675147 \\
.675147 \\
.274581 \\
.274581\end{array}$ \\
\hline VMTPC-GDPPC & $\begin{array}{l}.3523781+.5678486 \mathrm{i} \\
.3523781-.5678486 \mathrm{i} \\
.2258035+.1902826 \mathrm{i} \\
.2258035+.1902826 \mathrm{i} \\
\end{array}$ & $\begin{array}{l}.668298 \\
.668298 \\
.295288 \\
.295288\end{array}$ \\
\hline VMT-PI & $\begin{array}{l}.386013+.5729198 \mathrm{i} \\
.386013-.5729198 \mathrm{i} \\
.2173896+.164387 \mathrm{i} \\
.2173896+.164387 \mathrm{i} \\
\end{array}$ & $\begin{array}{l}.690828 \\
.690828 \\
.272546 \\
.272546 \\
\end{array}$ \\
\hline VMTPC-PIPC & $\begin{array}{l}.3532957+.5679065 \mathrm{i} \\
.3532957-.5679065 \mathrm{i} \\
.2276286+.1871313 \mathrm{i} \\
.2276286+.1871313 \mathrm{i}\end{array}$ & $\begin{array}{l}.668832 \\
.668832 \\
.294674 \\
.294674\end{array}$ \\
\hline \multicolumn{3}{|c|}{ Aggregated Subsample of UA's and Associated MSA's Data (1982-2009) $(n=98)$} \\
\hline VMT-PI & $\begin{array}{c}.9173188+.09394279 \mathrm{i} \\
.9173188-.09394279 \mathrm{i} \\
-.496322 \\
.17858\end{array}$ & $\begin{array}{l}.922117 \\
.922117 \\
.496322 \\
.17858\end{array}$ \\
\hline
\end{tabular}




\begin{tabular}{l|c|c}
\hline & .8973181 & .897318 \\
VMTPC-PIPC & $.6931843+.3733022 \mathrm{i}$ & .787311 \\
& $.6931843-.3733022 \mathrm{i}$ & .787311 \\
& -.3695244 & .369524 \\
\hline \multicolumn{2}{c|}{ Urban Subsample Divided into Population Groupings (1982-2009) (n=98) } \\
\hline & .8831655 & .883166 \\
VMTPC(vlg)-PIPC(vlg) & $.7010097+.3111598 \mathrm{i}$ & .766965 \\
& $.701009 \AA-.3111598 \mathrm{i}$ & .766965 \\
& -.3236217 & .323622 \\
\hline \multirow{3}{*}{ VMTPC(lrg)-PIPC(lrg) } & .872843 & .872843 \\
& $.7905867+.283594 \mathrm{i}$ & .839912 \\
& $.7905867-.283594 \mathrm{i}$ & .839912 \\
& -.3983964 & .398396 \\
\hline \multirow{2}{*}{ VMTPC(med)-PIPC(med) } & .8902946 & .890295 \\
& $.5018687+.3658767 \mathrm{i}$ & .621078 \\
& $.5018687-.3658767 \mathrm{i}$ & .621078 \\
& -.2982423 & .298242 \\
\hline & .9140482 & .914048 \\
VMTPC(sml)-PIPC(sml) & $.5340066+.3280137 \mathrm{i}$ & .626702 \\
& $.5340066-.3280137 \mathrm{i}$ & .626702 \\
& -.4276883 & .427688 \\
\hline
\end{tabular}

* Represents eigenvalues greater than one (*: do not satisfy stability condition).

Figure B.1: Unit Circle Graphs for Stability of Eigenvalues

\begin{tabular}{ll} 
Figure B.1: Unit Circle Graphs for Stability of Eigenvalues \\
\hline \\
\hline National Data (1929-2009)
\end{tabular}




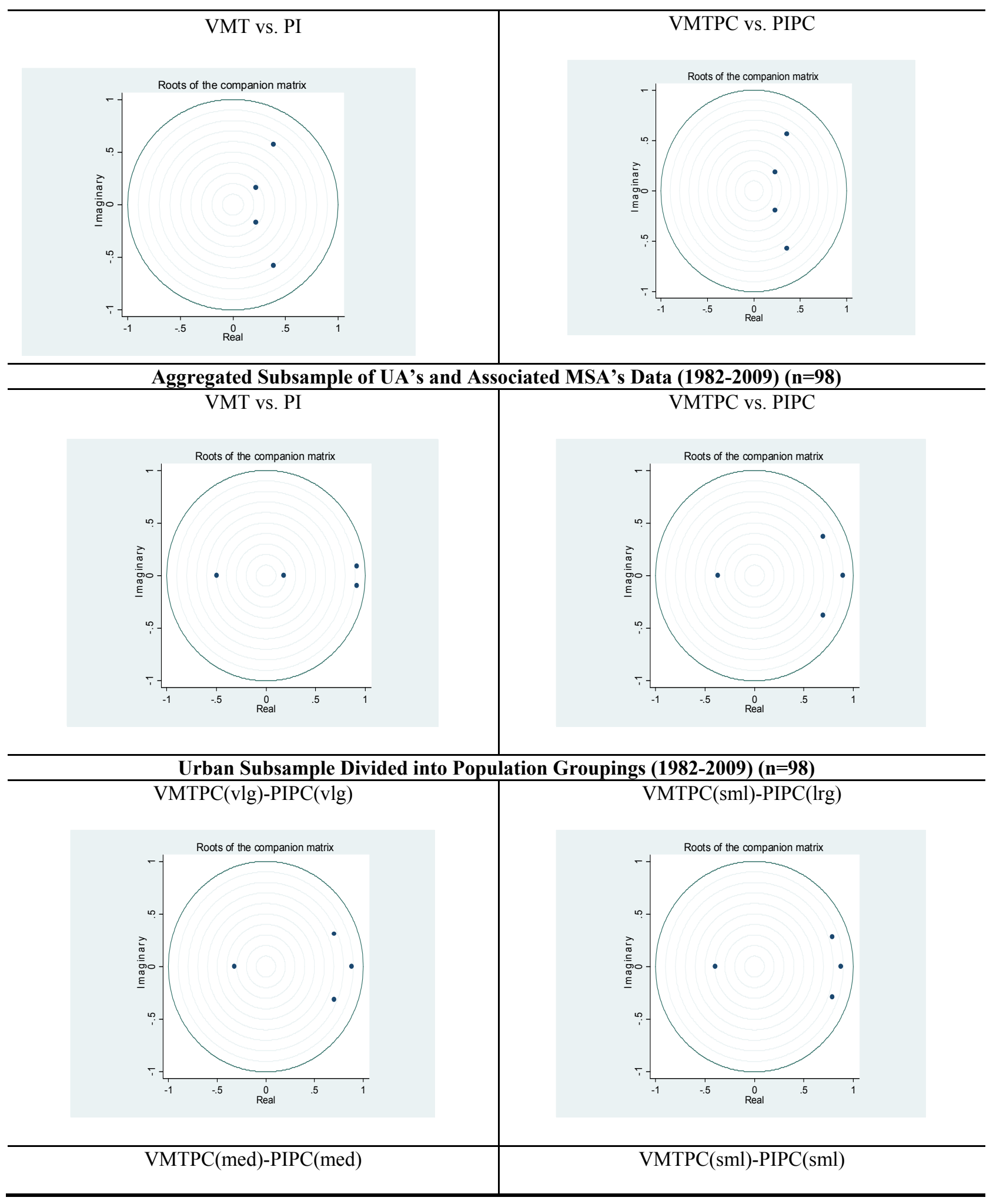




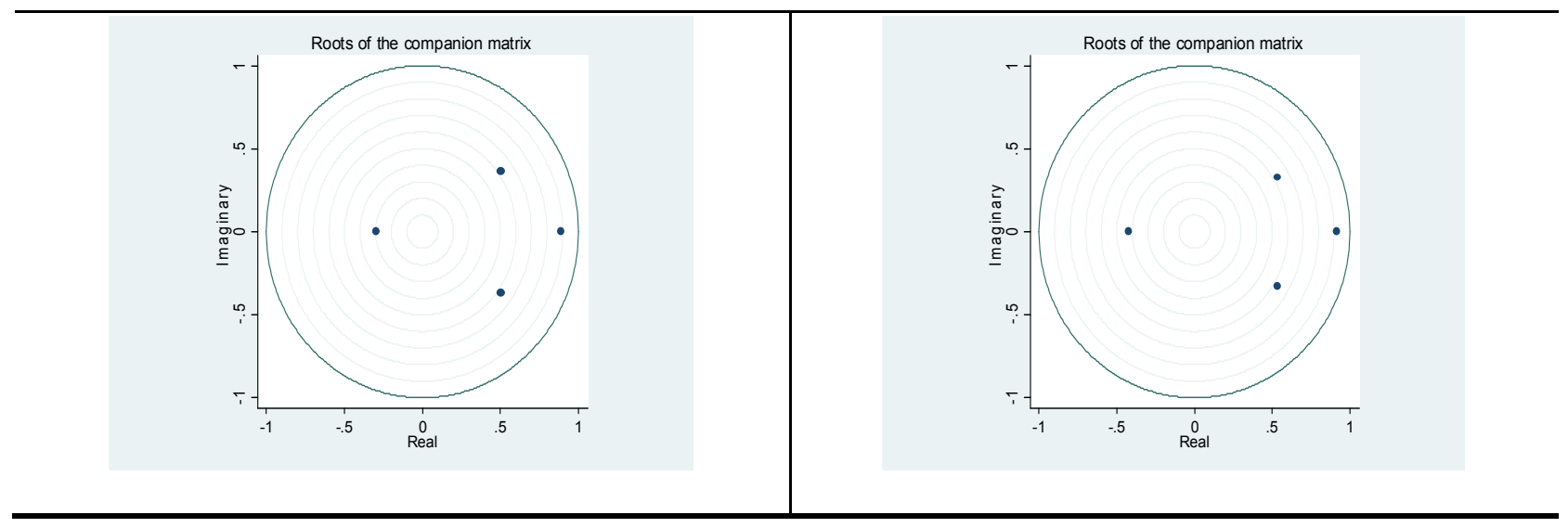




\section{APPENDIX C}

\section{IMPULSE RESPONSE ANALYSIS}

Impulse response functions describe how a variable reacts over time to an exogenous shock or impulse. In this study the impulse will represent a negative shock to total VMT, resulting from a policy passed in order to reduce GHGs or other externalities caused by excess driving. Thus, the one unit exogenous shock is placed on $V M T$, and the impulse response had by GDP or $P I$ is observed, starting at the time of the shock and lasting as long as 20 years.

Figure C.1 presents graphs of the impulses responses of economic activity after a one unit positive shock in VMT. Due to time restraints and lack of impulse response function programming experience the exogenous shock to VMT is positive and not negative, as would be ideal in the simulation of a GHG policy. Yet, the impulse responses can be inverted in order to rudimentally forecast economic activity. What is more important to witness than the direction of the forecast, is the scale of the response, and that in every regression by the 10-year mark almost all variation has subsided. This is in contrast to Pozdena's (2009) finding that a downward shock to VMT, would result in a reduction of GDP of 90 percent of the size of the VMT shock in the short run (two years) and 46 percent of the size in the long run (20 years) (Pozdena, 2009).

Table C.1 support the conclusion that GHG policies will not likely have large adverse effects on the economy due to VMT reduction by providing short-run (two year), mid-run (10 year), and long-run (20 year) impulse response estimates derived from Figure C.1. At the national level, the impulse response functions report that a downward shock to $V M T$ would result in an increase of GDP of .05 percent of the size of the VMT shock in the short run (two years) and have no effect in the long run (20 years) (Eckstein, 2011).

Table C.1: Impulse Response Functions (0-20 years post an exogenous VMT shock)

\begin{tabular}{l|c|c|c|c}
\hline \multicolumn{5}{c}{ National Data (1929-2009) } \\
\hline Step & VMT-GDP & VMTPC-GDPPC & VMT-PI & VMTPC-PIPC \\
\hline 2 year & -.000371 & -.000567 & -.000972 & -.001638 \\
\hline 10 year & .000415 & .000372 & .000427 & .000303 \\
\hline 20 year & $-7.5 e-06$ & $-4.9 \mathrm{e}-06$ & -.000011 & $-4.7 \mathrm{e}-06$ \\
\hline \multicolumn{5}{|c|}{ Aggregated Subsample of 98 Urban Area's Data (1982-2009) (n=98) } \\
\hline Step & VMT-GDP & VMTPC-GDPPC & VMT-PI & VMTPC-PIPC \\
\hline 2 year & - & - & .003427 & .005963 \\
\hline 10 year & - & - & .000212 & -.000837 \\
\hline 20 year & - & - & -.000448 & -.000171 \\
\hline \multicolumn{7}{|c|}{ Urban Subsample Divided into Population Groupings (1982-2009) (n=98) } \\
\hline Step & VMTPC(vlg)- & VMTPC(lrg)- & VMTPC(med)- & VMTPC(sml)- \\
\hline 2 year & PIPC(vlg) & PIPC(lrg) & PIPC(med) & PIPC(sml) \\
\hline 10 year & .007119 & .008274 & .002605 & .003022 \\
\hline 20 year & -.001277 & -.002425 & -.000119 & -.000211 \\
\hline
\end{tabular}


Figure C.1: Impulse Response Function Graph (0-20 years post exogenous VMT shock)

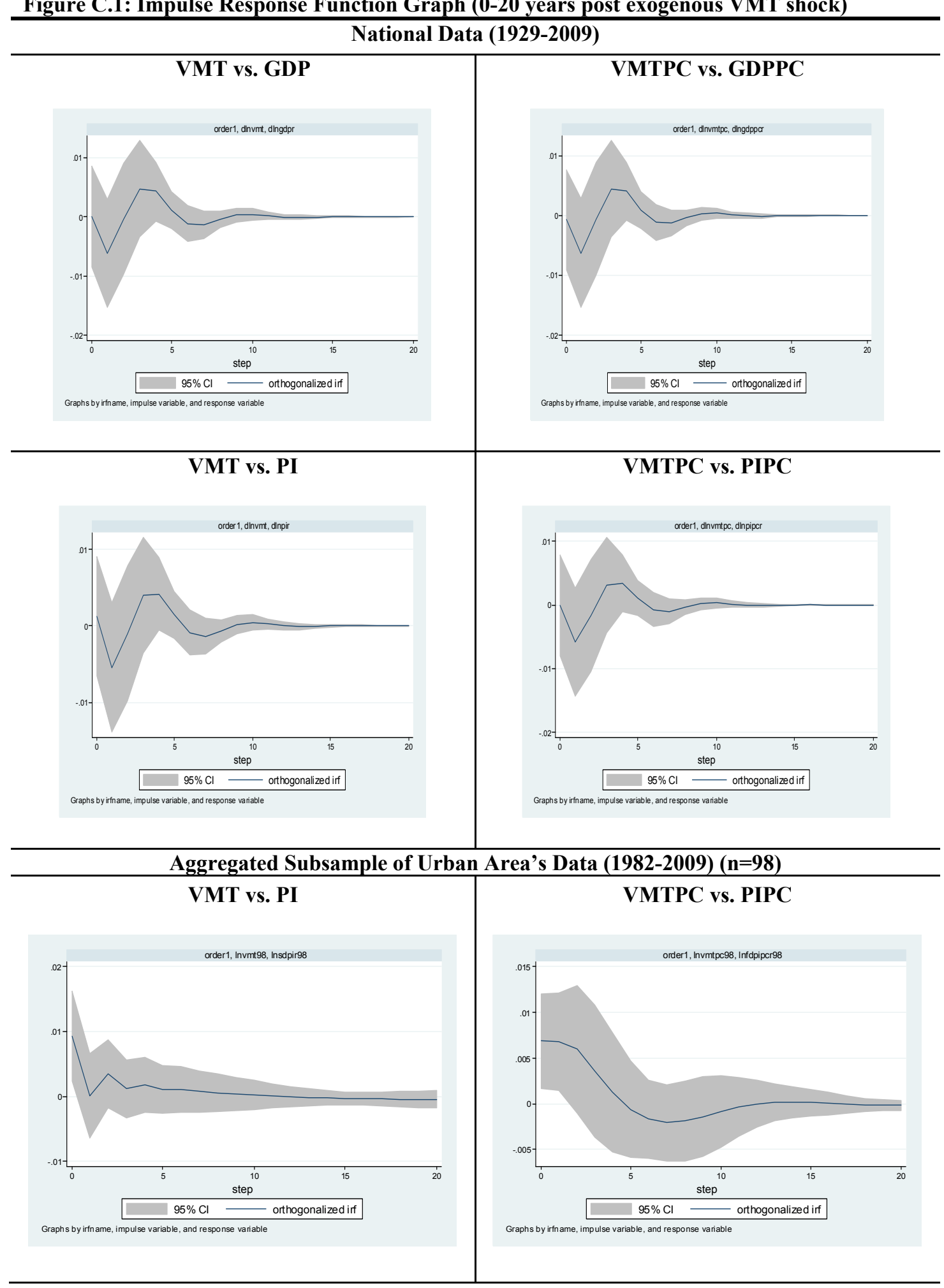




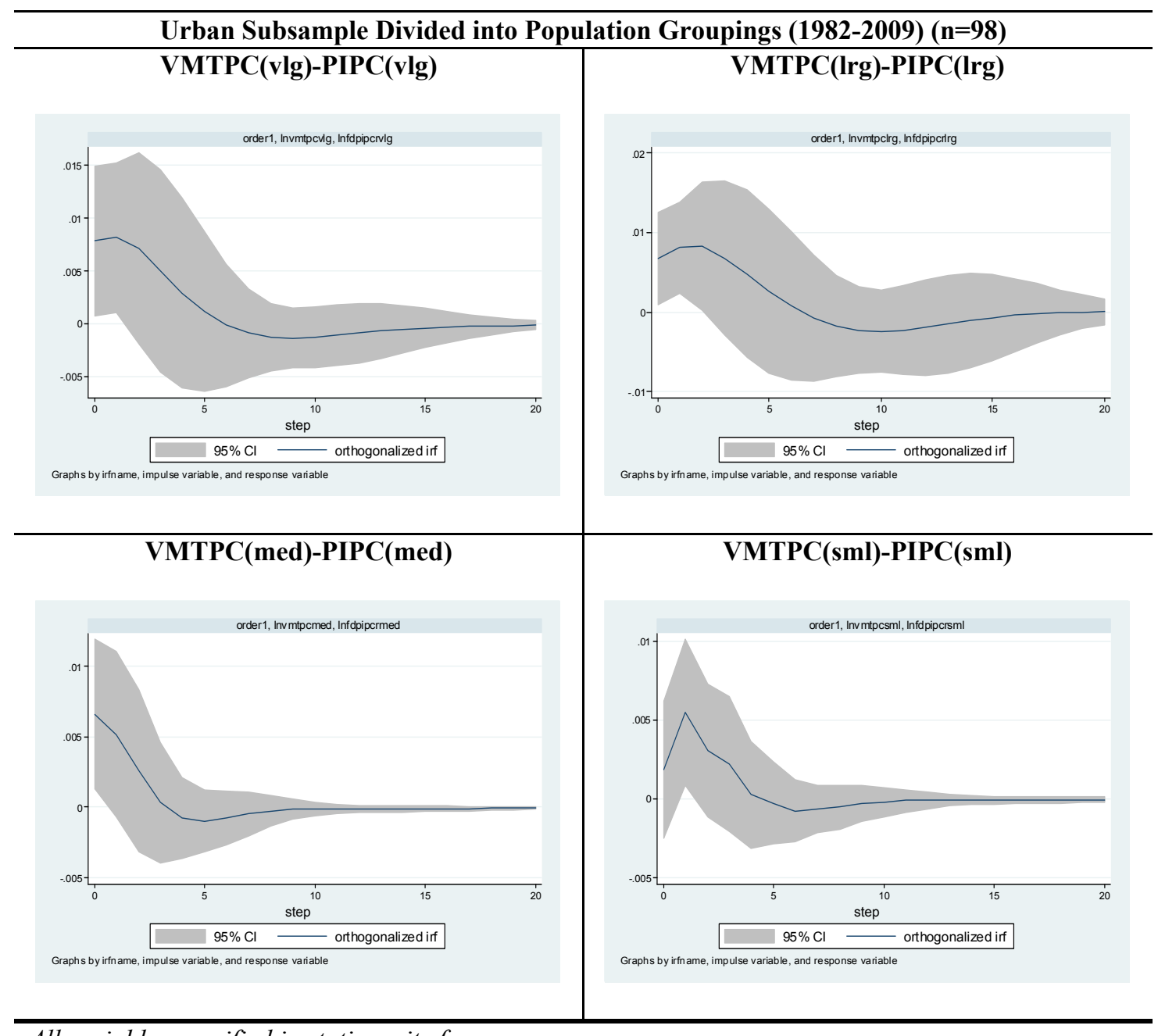

All variables specified in stationarity form. 
A-10 


\section{APPENDIX D}

\section{COEFFICIENTS FOR THE GROUP AND YEARLY FIXED EFFECTS}

Table D.1: Coefficients for the Group and Yearly Fixed Effects from Table 5.6-Column (D) (1982-2009)

\begin{tabular}{|c|c|c|}
\hline Variable Name (Fixed Effects) & Coefficients & T-Statistics \\
\hline \multicolumn{3}{|c|}{ Yearly Fixed Effects } \\
\hline 1983 & 0.0110 & 1.09 \\
\hline 1984 & 0.0102 & 0.94 \\
\hline 1985 & $0.0322 *$ & 2.77 \\
\hline 1986 & 0.0146 & 0.82 \\
\hline 1987 & 0.0286 & 1.57 \\
\hline 1988 & $0.0475^{*}$ & 2.45 \\
\hline 1989 & $0.0645^{*}$ & 3.46 \\
\hline 1990 & $0.0757 *$ & 3.66 \\
\hline 1991 & $0.0938^{*}$ & 4.56 \\
\hline 1992 & $0.1118^{*}$ & 5.28 \\
\hline 1993 & $0.1256^{*}$ & 5.63 \\
\hline 1994 & $0.1300^{*}$ & 5.37 \\
\hline 1995 & $0.1488^{*}$ & 6.56 \\
\hline 1996 & $0.1637^{*}$ & 7.57 \\
\hline 1997 & $0.1586^{*}$ & 6.68 \\
\hline 1998 & $0.1444 *$ & 5.32 \\
\hline 1999 & $0.1583 *$ & 6.1 \\
\hline 2000 & $0.1888^{*}$ & 9.27 \\
\hline 2001 & $0.1874 *$ & 8.65 \\
\hline 2002 & $0.1833^{*}$ & 7.58 \\
\hline 2003 & $0.2005^{*}$ & 8.85 \\
\hline 2004 & $0.2351^{*}$ & 12.59 \\
\hline 2005 & $0.2560 *$ & 14.99 \\
\hline 2006 & $0.2550 *$ & 14.76 \\
\hline 2007 & $0.2689 *$ & 15.53 \\
\hline 2008 & $0.2733^{*}$ & 15.52 \\
\hline 2009 & $0.2218 *$ & 12.94 \\
\hline \multicolumn{3}{|c|}{ Urban Area Fixed Effects } \\
\hline Albany-Schenectady-Troy, NY & $0.0456 *$ & 2.32 \\
\hline Albuquerque, NM & $0.1933 *$ & 9.91 \\
\hline Allentown-Bethlehem-Easton, PA-NJ & $0.0854 *$ & 4.37 \\
\hline Anchorage, AK & -0.0309 & -1.43 \\
\hline Atlanta-Sandy Springs-Marietta, GA & $0.4055^{*}$ & 19.27 \\
\hline Austin-Round Rock-San Marcos, TX & $0.1980 *$ & 10.11 \\
\hline Bakersfield-Delano, CA & -0.0195 & -0.88 \\
\hline Baltimore-Towson, MD & $0.2719^{*}$ & 11.24 \\
\hline Beaumont-Port Arthur, TX & $0.0678^{*}$ & 2.91 \\
\hline Birmingham-Hoover, AL & $0.2714 *$ & 14.11 \\
\hline Boston-Cambridge-Quincy, MA-NH & $0.2174 *$ & 9.31 \\
\hline Boulder, $\mathrm{CO}$ & $-0.0535^{*}$ & -2.10 \\
\hline Bridgeport-Stamford-Norwalk, CT & $0.1234^{*}$ & 4.33 \\
\hline
\end{tabular}




\begin{tabular}{|c|c|c|}
\hline Brownsville-Harlingen, TX & $-0.2388^{*}$ & -7.75 \\
\hline Buffalo-Niagara Falls, NY & $-0.1715^{*}$ & -9.30 \\
\hline Cape Coral-Fort Myers, FL & 0.0078 & 0.32 \\
\hline Charleston-North Charleston-Summerville, SC & $0.2498 *$ & 10.63 \\
\hline Charlotte-Gastonia-Rock Hill, NC-SC & $0.1560^{*}$ & 8.08 \\
\hline Chicago-Joliet-Naperville, IL-IN-WI & $-0.0639^{*}$ & -2.65 \\
\hline Cincinnati-Middletown, OH-KY-IN & $0.1714 *$ & 9.29 \\
\hline Cleveland-Elyria-Mentor, $\mathrm{OH}$ & $0.1187 *$ & 5.91 \\
\hline Colorado Springs, CO & -0.0068 & -0.30 \\
\hline Columbia, SC & $0.2414 *$ & 12.88 \\
\hline Columbus, $\mathrm{OH}$ & $0.2909 *$ & 15.14 \\
\hline Corpus Christi, TX & $0.0829 *$ & 3.64 \\
\hline Dallas-Fort Worth-Arlington, TX & $0.3127 *$ & 16.60 \\
\hline Dayton, $\mathrm{OH}$ & $0.1972 *$ & 10.65 \\
\hline Denver-Aurora-Broomfield, $\mathrm{CO}$ & $0.2369 *$ & 11.33 \\
\hline Detroit-Warren-Livonia, MI & $0.2904 *$ & 13.76 \\
\hline El Paso, TX & $0.0837 *$ & 3.44 \\
\hline Eugene-Springfield, OR & $0.1067 *$ & 5.20 \\
\hline Fresno, CA & $0.0884^{*}$ & 3.99 \\
\hline Grand Rapids-Wyoming, MI & $0.1482 *$ & 7.96 \\
\hline Hartford-West Hartford-East Hartford, CT & $0.1206^{*}$ & 5.96 \\
\hline Honolulu, HI & $0.2807 *$ & 8.77 \\
\hline Houston-Sugar Land-Baytown, TX & $0.3109 *$ & 15.54 \\
\hline Indianapolis-Carmel, IN & $0.3995^{*}$ & 21.87 \\
\hline Jacksonville, FL & $0.3323 *$ & 18.00 \\
\hline Kansas City, MO-KS & $0.3001 *$ & 15.58 \\
\hline Knoxville, TN & $0.3702 *$ & 19.13 \\
\hline Laredo, TX & $-0.2578^{*}$ & -8.36 \\
\hline Las Vegas-Paradise, NV & $0.1278 *$ & 4.56 \\
\hline Little Rock-North Little Rock-Conway, AR & $0.2979 *$ & 16.06 \\
\hline Los Angeles-Long Beach-Santa Ana, CA & $0.4855^{*}$ & 17.51 \\
\hline Louisville-Jefferson County, KY-IN & $0.3435^{*}$ & 17.24 \\
\hline Memphis, TN-MS-AR & $0.1323 *$ & 7.05 \\
\hline Miami-Fort Lauderdale-Pompano Beach, FL & $0.2039 *$ & 9.39 \\
\hline Milwaukee-Waukesha-West Allis, WI & $0.0660 *$ & 3.27 \\
\hline Minneapolis-St. Paul-Bloomington, MN-WI & $0.2218^{*}$ & 11.13 \\
\hline Nashville-Davidson-Murfreesboro-Franklin, TN & $0.3823 *$ & 20.86 \\
\hline New Haven-Milford, CT & $0.1754 *$ & 9.28 \\
\hline New Orleans-Metairie-Kenner, LA & 0.0033 & 0.14 \\
\hline New York-Northern New Jersey-Long Island, NY-NJ & -0.0532 & -1.75 \\
\hline Oklahoma City, OK & $0.2532 *$ & 13.55 \\
\hline Omaha-Council Bluffs, NE-IA & 0.0098 & 0.49 \\
\hline Orlando-Kissimmee-Sanford, FL & $0.3457 *$ & 17.89 \\
\hline Oxnard-Thousand Oaks-Ventura, CA & $0.3603 *$ & 16.78 \\
\hline Pensacola-Ferry Pass-Brent, FL & $0.1496^{*}$ & 6.99 \\
\hline Philadelphia-Camden-Wilmington, PA-NJ-DE & $0.1114^{*}$ & 4.82 \\
\hline Phoenix-Mesa-Glendale, AZ & $0.2234 *$ & 11.42 \\
\hline Pittsburgh, PA & $0.0687 *$ & 3.53 \\
\hline Portland-Vancouver-Hillsboro, OR-WA & $0.2500 *$ & 11.39 \\
\hline Poughkeepsie-Newburgh-Middletown, NY & $0.2694 *$ & 14.23 \\
\hline Providence-New Bedford-Fall River, RI-MA & 0.0100 & 0.51 \\
\hline Raleigh-Cary, NC & $0.2412 *$ & 12.70 \\
\hline
\end{tabular}




\begin{tabular}{l|c|c}
\hline Richmond, VA & $0.1755^{*}$ & 9.55 \\
\hline Riverside-San Bernardino-Ontario, CA & $0.3578^{*}$ & 15.84 \\
\hline Rochester, NY & $-0.1383^{*}$ & -7.26 \\
\hline Sacramento-Arden-Arcade-Roseville, CA & $0.3740^{*}$ & 15.65 \\
\hline Salem, OR & $0.2981^{*}$ & 15.63 \\
\hline Salt Lake City, UT & $0.0992^{*}$ & 4.28 \\
\hline San Antonio-New Braunfels, TX & $0.2328^{*}$ & 11.52 \\
\hline San Diego-Carlsbad-San Marcos, CA & $0.2878^{*}$ & 13.22 \\
\hline San Francisco-Oakland-Fremont, CA & $0.4770^{*}$ & 19.17 \\
\hline San Jose-Sunnyvale-Santa Clara, CA & $0.3984^{*}$ & 14.00 \\
\hline Seattle-Tacoma-Bellevue, WA & $0.4073^{*}$ & 14.65 \\
\hline Spokane, WA & $0.3381^{*}$ & 15.71 \\
\hline Springfield, MA & -0.0155 & -0.77 \\
\hline St. Louis, MO-IL & $0.0514^{*}$ & 2.78 \\
\hline Tampa-St. Petersburg-Clearwater, FL & $0.1738^{*}$ & 8.70 \\
\hline Toledo, OH & 0.0241 & 1.34 \\
\hline Tucson, AZ & $0.1879^{*}$ & 7.90 \\
\hline Tulsa, OK & $0.1333^{*}$ & 7.14 \\
\hline Virginia Beach-Norfolk-Newport News, VA-NC & $0.1668^{*}$ & 7.65 \\
\hline Washington-Arlington-Alexandria, DC-VA-MD & $0.2757^{*}$ & 9.14 \\
\hline Wichita, KS & $-0.0654^{*}$ & -3.49 \\
\hline Base year and area: & &
\end{tabular}

Base year and area: 1982 and Akron, $\mathrm{OH}$.

* Represents statistical significance at the 5\% level. 
A-14 



\section{GOTREC \\ AND EDUCATION CONSORTIUM}

P.O. Box 751

Portland, OR 97207

OTREC is dedicated to stimulating and conducting collaborative multi-disciplinary research on multi-modal surface transportation issues, educating a diverse array of current practitioners and future leaders in the transportation field, and encouraging implementation of relevant research results. 